\title{
Quality of life in patients with allergic and immunologic skin diseases: in the eye of the beholder
}

\author{
Ester Di Agosta', Lorenzo Salvati' , Monica Corazza², Ilaria Baiardini ${ }^{3,4}$, Francesca Ambrogio5 ${ }^{5}$, Luisa Angileri' \\ Elettra Antonelli ${ }^{7}$, Federica Belluzzo ${ }^{8}$, Domenico Bonamonte ${ }^{9}$, Laura Bonzano ${ }^{10}$, Raffaele Brancaccio ${ }^{11}$, \\ Paolo Custurone ${ }^{12}$, Aurora De Marco ${ }^{9}$, Aikaterini Detoraki ${ }^{13}$, Adriana Di Guida ${ }^{14}$, Elisabetta Di Leo ${ }^{15}$, \\ Marta Fantò ${ }^{16}$, Filippo Fassio ${ }^{17}$, Silvia Mariel Ferrucci ${ }^{6}$, Caterina Foti ${ }^{5}$, Rosella Gallo ${ }^{18}$, Alessia Gatta ${ }^{19}$, \\ Fabrizio Guarneri ${ }^{12}$, Lucia Guidolin ${ }^{20}$, Katharina Hansel ${ }^{7}$, Donatella Lamacchia ${ }^{4}$, Carla Lombardo ${ }^{21}$, \\ Paola Lucia Minciullo22, Maddalena Napolitano ${ }^{23}$, Alessandro Pannofino ${ }^{24}$, Andrea Paravisi ${ }^{25}$, \\ Roberta Parente ${ }^{26}$, Maria Passante ${ }^{27}$, Cataldo Patruno ${ }^{27}$, Diego Peroni ${ }^{28}$, Cristina Quecchia ${ }^{29}$, Natale Schettini ${ }^{2}$, \\ Giuseppe Spadaro ${ }^{30}$, Luca Stingeni ${ }^{7}$, Daniele Tarrini ${ }^{31}$, Marta Tramontana ${ }^{7}$, Eustachio Nettis ${ }^{32}$ and \\ Oliviero Rossi $3^{33^{*}}$
}

\begin{abstract}
Allergic and immunologic skin diseases negatively impact the quality of life (QoL) of affected patients with detrimental consequences. Nonetheless, in everyday clinical practice the evaluation of QoL is often overlooked. Considering the increasing prevalence of atopic dermatitis, allergic contact dermatitis, hereditary angioedema, cutaneous mastocytosis, and urticaria, it is essential to determine the effects of allergic and immunologic skin diseases on QoL. A joint meeting (GETTOGETHER 2021) of the Italian Society of Allergology, Asthma and Clinical Immunology (SIAAIC) and the Italian Society of Allergological, Occupational and Environmental Dermatology (SIDAPA) aimed to summarize the features of the main QoL tools used in these diseases and to describe the extent of QoL impairment as well as the impact of treatments on QoL, particularly biologic therapies. The assessment of QoL in patients with allergic and immunologic skin diseases relies on generic, organ-specific and disease-specific questionnaires. While generic and organ-specific questionnaires allow comparison between different diseases, disease-specific questionnaires are designed and validated for specific cohorts: the QoL Index for Atopic Dermatitis (QoLIAD) and the Childhood Atopic Dermatitis Impact Scale (CADIS) in atopic dermatitis, the ACD-11 in allergic contact dermatitis, the Angioedema QoL Questionnaire (AE-QOL) and the Hereditary Angioedema QoL questionnaire (HAE-QoL) in hereditary angioedema, the Mastocytosis QoL Questionnaires (MCQoL e MQLQ) in cutaneous mastocytosis, and the Chronic Urticaria QoL questionnaire (CU-Q2oL) in urticaria. Among the many factors that variably contribute to QoL impairment, pruritus can represent the leading cause of patient discomfort. Biologic therapies significantly ameliorate QoL in atopic dermatitis, hereditary angioedema, mastocytosis and chronic urticaria. In general, adequate management strategies are essential for improving QoL in patients with allergic and immunologic skin diseases.
\end{abstract}

\footnotetext{
${ }^{*}$ Correspondence: oliviero.rossi@unifi.it

33 Immunoallergology Unit, SOD Immunoallergologia, Azienda Ospedaliero-Universitaria Careggi, Firenze, Italy

Full list of author information is available at the end of the article
}

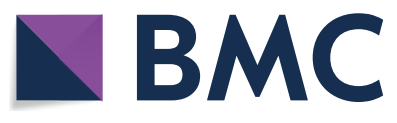

(c) The Author(s) 2021. Open Access This article is licensed under a Creative Commons Attribution 4.0 International License, which permits use, sharing, adaptation, distribution and reproduction in any medium or format, as long as you give appropriate credit to the original author(s) and the source, provide a link to the Creative Commons licence, and indicate if changes were made. The images or other third party material in this article are included in the article's Creative Commons licence, unless indicated otherwise in a credit line to the material. If material is not included in the article's Creative Commons licence and your intended use is not permitted by statutory regulation or exceeds the permitted use, you will need to obtain permission directly from the copyright holder. To view a copy of this licence, visit http://creativecommons.org/licenses/by/4.0/. The Creative Commons Public Domain Dedication waiver (http://creativeco mmons.org/publicdomain/zero/1.0/) applies to the data made available in this article, unless otherwise stated in a credit line to the data. 
Keywords: Quality of life, Atopic dermatitis, Allergic contact dermatitis, Hereditary angioedema, Cutaneous mastocytosis, Urticaria, Skin, Allergy

\section{Background}

"The value of experience is not in seeing much, but in seeing wisely" Sir William Osler [1849-1919]

Quality of life (QoL) of patients with allergic and immunologic skin diseases is often a neglected issue in clinical practice [1]. The GET TOGETHER 2021 meeting, organized by SIAAIC (Società Italiana di Allergologia, Asma ed Immunologia Clinica) and SIDAPA (Società Italiana di Dermatologia Allergologica, Professionale e Ambientale) was a virtual meeting held by specialists in allergic and immunologic skin diseases in Italy between May and June 2021 with the primary aim to discuss and review the current knowledge on the QoL of patients with atopic dermatitis, allergic contact dermatitis, hereditary angioedema, cutaneous mastocytosis, and urticaria. Considering the increasing prevalence of allergic and immunologic skin disorders, it becomes fundamental to evaluate their impact on the QoL of affected patients, as well as the effect of current therapies on QoL.

\section{Main text}

Generic Questionnaires: assessing QoL in patients with allergic and immunologic skin diseases

Generic questionnaires are designed to assess health related quality of life (HRQoL) in wide populations with or without chronic conditions and they allow comparing different diseases $[2,3]$. The most used are the Short Form 36 Health Survey (SF-36), the EuroQol-5D (EQ5D) and the Nottingham Health Profile (NHP).

- The Short Form 36 Health Survey (SF-36) is a selfadministered, multidimensional, well validated and widely used generic instrument [3]. It consists of 36 items relating to eight dimensions (physical function, role-physical function, bodily pain, general health perceptions, vitality, social functioning, role-emotional function and mental health), one physical component score and one mental component score. The eight-dimension score range is $0-100$, with higher scores indicating higher levels of function andor better health. The SF-36 also includes a general health rating item, which inquires about the change in general health over the last year [4].

- The EuroQol-5D (EQ-5D) is a generic and synthetic measure of the HRQoL. It essentially consists of two parts: the EQ-5D descriptive system and the EQ vis- ual analogue scale (EQ VAS). The EQ-5D descriptive system comprises five dimensions: mobility, self-care, usual activities, pain/discomfort and anxiety/depression [5]. Each dimension is analyzed according to different graduated levels: EQ-5D-3L (no, some, or extreme problems) and EQ-5D-5L (no, slight, moderate, severe, or extreme problems). The EQ VAS records the patient's self-rated health on a vertical VAS where the endpoints are labelled as "best imaginable health state" and "worst imaginable health state" [5].

- The Nottingham Health Profile (NHP) was developed for measuring the impact of disease on patients and the assessment of changes in health status over time. It provides a brief indication of a patient's perceived emotional, social, and physical health and is intended for use in the general population. The NHP is composed of two parts that can be used together or separately, with the first part frequently used on its own. The domains covered in the first part are related to health status, while the second part addresses the impact of disease on daily life [6].

Organ-specific questionnaires investigate one system, differently from generic or disease-specific questionnaires. Their advantage is the application for assessment of different dermatological diseases; however some skin diseases also involve other organs not considered in these skin-specific tools [2]. In dermatology, commonly used organ-specific instruments include the Dermatology Life Quality Index (DLQI), the Skindex-29 and the Dermatology-Specific Quality of Life (DSQL).

- The Dermatology Life Quality Index (DLQI) and the corresponding Children's Dermatology Life Quality Index (CDLQI) used for patients $<16$ years, are selfadministered questionnaires consisting of 10 questions concerning the impact of skin diseases on different aspects of patient's QoL over the last week [7]. The DLQI items include symptoms and feelings, daily activities, leisure, work or school, personal relationships and the side effects of treatment [7].

- The Skindex-29 was designed to measure healthrelated QoL in skin conditions, allowing changes over time to be detected. Its final version consists of 29 distinct questions in three categories: emotions, activities and symptoms. Subsequently, two short versions were developed (Skindex-16 and Skin- 
dex-17), originated from two different sub-categories: psycho-social and symptoms [4].

- The Dermatology-Specific Quality of Life (DSQL) provides valid and reliable assessments of QoL impairment associated with acne and contact dermatitis; it is used to quantify the effects of skin disease on physical discomfort and symptoms, psychological wellbeing, social functioning, self-care activities, performance at work or school, and self-perceptions $[8,9]$.

\section{Quality of life in patients with atopic dermatitis}

Atopic dermatitis (AD) is a common inflammatory skin disease characterized by intense pruritus and recurrent eczematous lesions that affects both children and adults [10]. Itching represents the main cause of patient discomfort [11]. AD extensively interferes with sleep: patients have difficulties in falling asleep, tend to awake at night and have reduced sleep hours with consequent daytime sleepiness, reduced work or school performance and irritability [11]. The emotional and behavioral domains are also affected. In children, AD interferes with physical abilities (poor participation in sports activities), often changing relationships with peers and teachers, but the entire family is involved in terms of lower social support, higher stress, and greater difficulties in managing discipline $[12,13]$. As a result, the psychological development of the child with AD can be impaired [13]. Age and gender can affect the different perception of QoL [14]. Severe $A D$ is associated with greater QoL impairment [15]. Often in $A D$, adequate anti-pruritic therapy determines QoL improvement.

\section{Atopic dermatitis-specific QoL tools}

The impact of $\mathrm{AD}$ on QoL can be measured using several QoL questionnaires: generic and organ-specific instruments are frequently used. Among these, the DLQI has been recommended by the HOME initiative as the core instrument for measuring the impact of $\mathrm{AD}$ on the QoL of adult patients with AD [16]. The Quality of Life Index for Atopic Dermatitis (QoLIAD), is a disease-specific patient reported outcome for adult $\mathrm{AD}$ patients. It includes 25 questions with dichotomous answers, which makes it simple and practical to use even in clinical practice [17]. Several dermatology specific and AD-specific validated instruments measure the impact of QoL on family members of AD patients. Among these, the Childhood Atopic Dermatitis Impact Scale (CADIS) is a disease-specific QoL scale with 45 items for children with AD younger than 6 years and for their parents, exploring 5 domains: child symptoms, child activity limitations and behavior, family and social function, parent sleep, and parent emotions [13].

\section{Impact of treatment on QoL in patients with atopic dermatitis} The goals of treatment are to reduce symptoms (pruritus and dermatitis), to prevent exacerbations and to minimize therapeutic risks. Standard treatment modalities for the management of these patients are centered around the use of topical anti-inflammatory preparations and moisturization of the skin, but patients with severe disease may require phototherapy or systemic treatment [18]. Based on the growing understanding of the pathomechanisms of $\mathrm{AD}$, several biologics and small molecules targeting various AD-related pathways are being investigated in clinical trials [19]. Among these, dupilumab, a monoclonal antibody directed against the interleukin-4 receptor subunit $\alpha$ (IL-4R $\alpha$ ) of IL-4 and IL-13 receptors, is the only biologic therapy that is Food and Drug Administration approved for the treatment of moderate-to-severe AD in patients 6 years and older, with consistent long-term efficacy and safety trial data. In the first clinical trials with dupilumab in monotherapy (SOLO 1 and SOLO 2), reduction in pruritus, reduction in symptoms of anxiety or depression (Hospital Anxiety and Depression Scale, HADS), and improvement in DLQI from baseline were significantly greater in the dupilumab group than in the placebo group at week 16 [20]. In another study, dupilumab-treated patients in monotherapy experienced a mean 7.2-point improvement in DLQI score, compared with 1.6-point improvement with placebo and a significantly greater proportion of dupilumab-treated patients had $\geq 4$-point reduction (improvement) in DLQI score than with placebo (59.3\% vs. $24.4 \%, p<0.001$ ) [21]. In CHRONOS trial, at 52 weeks an improvement of DLQI greater or equal to 4 points was achieved by $63 \%$ of patients treated with weekly dupilumab and topical corticosteroids and by $80 \%$ of patients treated with dupilumab every 2 weeks and topical corticosteroids, compared to $30 \%$ of patients treated with placebo and topical corticosteroids ( $p=0.0001$ ) [22]. Moreover, other studies showed significant reductions in pruritus (Numerical Rating Scale, NRS and scores for pain and discomfort (EQ-5D) in adult patients with $A D$ $[21,23]$. Similarly, a recent post hoc analysis revealed that adolescents with moderate to severe AD treated with dupilumab experienced statistically significant and clinically meaningful improvements in AD signs, symptoms (including pruritus and sleep loss), and QoL at week 16 compared with the palcebo group [24]. The results of the registrative studies of dupilumab, regarding the improvement of the items of the QoL questionnaires administered to enrolled patients, were also confirmed by real life studies that were subsequently carried out on different 
groups of patients (elderly, adolescents) $[25,26] . \mathrm{AD}$ is a complex and multifactorial disease with a significant impact on the QoL of affected patients as well as of their families. AD is not an easy condition with a straightforward, one-size-fits-all solution; however, in this new era of genetic and molecular discoveries, better tools to address this condition on an individualized basis will be available, thus further improving patient's QoL [27].

\section{Quality of life in patients with allergic contact dermatitis} Contact dermatitis (CD) is an inflammatory cutaneous disease characterized by skin lesions occurring after contact with an exogenous substance. Classically, it comprises two different forms: irritant contact dermatitis (ICD) and allergic contact dermatitis (ACD) $[28,29]$. The latter is a delayed hypersensitivity reaction triggered by skin contact with an allergen in previously sensitized patients [30]. In the acute phase, ACD is characterized by erythematous, edematous, and papulo-vesicular lesions, while scaling and lichenification are the typical clinical aspects of the chronic disease [28, 31]. Pruritus is the typical symptom of ACD. Despite the significant prevalence of ACD (it is estimated between 15 and $20 \%$ in the general population), the impact of this condition on QoL is poorly known and little has been published about the quantification of QoL of ACD patients [32, 33]. Assessment of the extent of QoL changes in patients with ACD is based on symptoms, feelings, function, occupation and treatment $[34,35]$. Patients with ACD reported being bothered most by eczematous skin lesions, itching and the predisposition to persistence of disease [31]. The clinical presentation, especially if localized on the hands or face, often causes reduced esteem by self and others with a high risk for depression and anxiety $[32,36]$ The impact on the QoL is greater, the greater the severity of disease [37]. Ayala et al. demonstrated that four main aspects (itching, discomfort, difficulty in carrying out daily activities, and difficulty using hands at work) are of utmost importance in influencing the QoL of CD patients. The more these features are negatively altered, the easier a poor QoL can be predicted, particularly for females when compared to males [38]. ACD patients with chronic severe hand eczema can have an important functional impact in terms of limitation in manual skills and difficulty in carrying out the common gestures of daily life, as buttoning up, opening a bottle, and in many other activities. Considering that ACD and ICD represent about $90 \%$ of occupational skin diseases, occupational setting, particularly if hands are affected, is also frequently impaired, contributing to lengthy absences from work ("sick-leave") and negatively impacting also in the socioeconomic area of the whole society [32]. In addition, ACD can result in "disability", meaning the loss of ability in doing the working activity as compared before the disease onset. ACD can consequently result in reduced productivity and loss of quality of work thus generating possible conflicts in the workplace [39]. It is not infrequent that ACD patients are forced to change job or type of working activity resulting sometimes in professional disqualification and economic disadvantage [39]. The psychosocial impact of ACD on QoL is relevant both in occupational and non-occupational ACD and includes mainly anxiety, depression and sleep disturbance, but also difficulties in fulfilling personal and family responsibilities and limitations in leisure activities $[35,40]$. The need for time (usually long-term) and economic investment (often charged to the patient) that must be dedicated to medical treatments impact negatively on QoL [41]. It is important to note that a timely indication of patch testing is critical to relieve patients' suffering and reduce cost of treatment [42-44]. Patch testing significantly improves QoL, both symptoms domain and emotional impact [35, 44-46]. Even patients with negative results seem to benefit from this diagnostic test [47]. QoL improves about 6 months after diagnosis but worsens after 12 months from patch testing [33]. An annual follow-up may improve QoL thanks to patients' education and constant evaluation of allergen exposures. ACD negatively impacts on the QoL of affected patients, however data on quantification of this significant burden are scarce. For this reason, we believe that an ACD-approach should be proposed in which the acronym ACD-in addition to the diseasedenotes three actions that clinicians should play: Ask, Contribute, and Deter. Asking about health status is an essential question during visits to ACD patients, a few more questions should be asked just to complete a specific QoL questionnaire. Contributing to the current knowledge with good quality data that explore QoL of ACD patients referred not only to university hospitals but also to other hospitals and outpatient clinics, it would be possible to reach consensus on a comprehensive, validated and ACD-specific QoL tool. Finally, detering from exposure to culprit allergens means prevention which is essential to improve QoL of patients with ACD.

\section{Allergic contact dermatitis-specific QoL tools}

The instruments available to assess the burden of ACD on the HRQoL of patients are questionnaires that range from generic to disease-specific [37, 45, 48-52]. The most commonly used dermatology-specific QoL questionnaires in patients with ACD are the DLQI $[39,53$, 54], the Skindex-29 or Skindex-16 [32, 33, 43, 55], and the DSQL $[9,56]$. The DSQL had been originally validated in patients with contact dermatitis, but its use in this patient population is limited in the literature [9, 37]. Contact dermatitis-specific questionnaires have been 
developed and include the Contact Dermatitis-Specific Questionnaire [38], the Fragrance Quality of Life Index (FQLI) [57-59], the Quality of Life in Hand Eczema Questionnaire (QOLHEQ) [41, 60], and the ACD-11 $[32,35]$. Among these tools, the ACD-11 has been specifically designed for patients with ACD [35]. Available contact dermatitis-specific questionnaires comprise different numbers of items, refer to different periods of time and have some limitations in patients with ACD, as outlined in Table 1. The evaluation of the impact of ACD on work productivity can be more precisely measured using the Work Productivity and Activity Impairment (WPAI) questionnaire and its various declinations $[39,53,61,62]$. Considering the pediatric population with ACD, available QoL tools include the CDLQI questionnaire [63].

\section{Impact of treatment on QoL in patients with allergic contact dermatitis}

The goal of treatment is the avoidance of the contact with the causative agent $[29,31]$. If the culprit allergen or irritant is not found or eliminated, the dermatitis may become chronic with negative impact and repercussions throughout several aspects of the life of affected people with a high disease burden [31,36]. Patient education about causes of contact allergy and avoidance of documented allergens and irritants represent the first line management approach. In case of mild disease, personal protective measures such as barrier creams, gloves and protective clothing, skin barrier repair cream, alcohol disinfection and addition of moisturizers (use of humectants and emollients) help to improve skin barrier. The mainstay of treatment is application of topical corticosteroids, often supplemented by moisturizing creams [64]. Topical calcineurin inhibitors (pimecrolimus, tacrolimus) and topical phosphodiesterase 4 inhibitor (crisaborole) are off-label use for CD but are known to be effective. In case of treatment failure, phototherapy could be considered. For moderate to severe localized dermatitis, topical anti-inflammatory treatment can be used as needed. Moreover, dietary avoidance and removal of airborne allergens may be of some benefit in recalcitrant forms of the disease [64]. The resistant nature of moderate to severe $\mathrm{CD}$ makes its management challenging. Phototherapy (narrow band UVB) or psoralen plus UVA (PUVA) can be used. Current systemic treatments include systemic corticosteroids (short term option) and other immunosuppressants (cyclosporine, methotrexate, azathioprine, mycophenolate mofetil). With advances in the understanding of the cellular and molecular pathogenesis of $\mathrm{CD}$, emerging biologic therapies with licensed indications for other eczematous and immunoinflammatory skin conditions may have a place in the treatment of recalcitrant cases of ACD [65]. Infliximab, a TNF- $\alpha$ inhibitor, has been tried in patients with recalcitrant atopic eczema with associated $C D[66,67]$. Dupilumab has been used successfully in systemic ACD to nickel and it has proven to be of value in the management of recalcitrant ACD $[68,69]$. Omalizumab, an antiIgE monoclonal antibody has been tried in recalcitrant protein $\mathrm{CD}$ to wheat [70]. The positive response to omalizumab in case of wheat allergy can be accounted to the fact that wheat allergy is a combination of type I and type IV hypersensitivity reactions. Anti-IgD antibodies are known to deplete B cells and modulate both Th1 and Th2 response and inhibit apparent skin inflammation when administered in allergen-challenged murine models: this finding could pave the way for anti-IgD antibodies to be tried as a therapeutic option in ACD [71]. Because ACD is an immunologically mediated disease, the role of biologics and other immunomodulators is undeniable [64, $65]$. Further use and research of biologics, especially in

Table 1 Quality-of-life specific instruments in patients with allergic contact dermatitis

\begin{tabular}{|c|c|c|c|c|c|}
\hline QoL specific tool & References [PMID] & $\begin{array}{l}\text { Total } \\
\text { no. } \\
\text { items }\end{array}$ & Recall period & Indications & $\begin{array}{l}\text { Limitations in patients with } \\
\text { ACD }\end{array}$ \\
\hline $\begin{array}{l}\text { Contact Dermatitis-Specific } \\
\text { Questionnaire }\end{array}$ & Ayala et al. [38] [20233546] & 20 & Last 6 months & $\begin{array}{l}\text { Patients with contact der- } \\
\text { matitis }\end{array}$ & Rarely used in the literature \\
\hline $\begin{array}{l}\text { Fragrance Quality of Life } \\
\text { Index (FQLI) }\end{array}$ & $\begin{array}{l}\text { Heisterberg et al. [57] } \\
\text { [24600708] }\end{array}$ & 13 & Currently & $\begin{array}{l}\text { Patients with fragrance } \\
\text { allergy }\end{array}$ & $\begin{array}{l}\text { Use is limited to fragrance- } \\
\text { related allergic contact } \\
\text { dermatitis }\end{array}$ \\
\hline $\begin{array}{l}\text { Quality of Life in Hand } \\
\text { Eczema Questionnaire } \\
\text { (QOLHEQ) }\end{array}$ & $\begin{array}{l}\text { Ofenloch et al. [41] } \\
\text { [24397866] }\end{array}$ & 30 & Last 7 days & Patients with hand eczema & $\begin{array}{l}\text { Use is limited to hand involve- } \\
\text { ment }\end{array}$ \\
\hline ACD-11 & Raffi et al. [35] [32049717] & 11 & Last 4 weeks & $\begin{array}{l}\text { Patients with allergic contact } \\
\text { dermatitis }\end{array}$ & $\begin{array}{l}\text { Symptoms domain does not } \\
\text { include pruritus, functioning } \\
\text { domain does not include work } \\
\text { impairment }\end{array}$ \\
\hline
\end{tabular}


cases of recalcitrant $\mathrm{CD}$, may identify new treatment modalities for $\mathrm{CD}$ in the near future.

\section{Quality of life in patients with hereditary angioedema} Hereditary angioedema (HAE), firstly described by Osler in 1888 as "hereditary angioneurotic oedema", is a rare genetic disease characterized by recurrent episodes of oedema of cutaneous and submucosal tissue, caused by temporary vasodilation, increased vascular permeability and flow of fluids into the extracellular space. A deficiency of the enzymatic activity of $\mathrm{C} 1$ esterase inhibitor (C1-INH), a protease inhibitor of the serpin superfamily, leads to an increased production of bradykinin, which is responsible for the clinical manifestations. Over 450 mutations in the C1-INH gene were reported [72], which lead to a reduced synthesis of C1-INH (HAE type I, $\sim 85 \%$ of cases) or quantitatively normal synthesis of functionally abnormal C1-INH (HAE type II, 15\% of cases). Moreover, in 2000, a dominantly inherited disease has been described that has a similar clinical picture to hereditary angioedema with $\mathrm{C} 1$ inhibitor deficiency (C1-INH-HAE), but with normal C1-INH level and activity [73]. This very rare condition is associated in some cases with mutations in the gene of coagulation factor XII, while other cases are yet of unknown origin. HAE presents with attacks of swelling of the face, larynx, tongue, extremities, stomach, intestines, and genitals, has a self-limiting course, and a variable duration. It is accompanied by intense pain and deformity of the involved sites, and, in some cases, fatal risk may occur, due to severe oedema of the larynx. Prodromal symptoms and signs such as fatigue, tingling and marginate erythema may sometimes be observed [74]. The unpredictability of the attacks, as well as intensity and severity of the symptoms, make the disease particularly impacting on the QoL of affected patients and their caregivers.
Attacks may be painful and debilitating, interfering with daily activities such as attending work or school and/or participating in social and family life. This entails a significant emotional distress and clinical burden on both patients and family members, causing a worsening of the QoL [75].

\section{Hereditary angioedema-specific QoL tools}

C1-INH-HAE experts recommend to measure HRQoL once a year, and the C1-INH-HAE guidelines of the World Allergy Organization state that HRQoL should be considered when assessing the need for prophylaxis [76, 77]. Currently, two angioedema-specific HRQoL questionnaires are available: the AE-QoL, specific for angioedema as a symptom, and the HAE-QoL, specific for adult patients with C1-INH-HAE (Table 2) [78].

\section{$A E-Q o L$}

The AE-QoL is the first specific patient-reported outcome tool to assess QoL impairment in adult patients with any kind of recurrent angioedema [79]. Nowadays, linguistically validated versions of $\mathrm{AE}-\mathrm{QoL}$ are available for several languages [80-83]. The AE-QoL includes 17 items, grouped into four dimensions and has a recall period of 4 weeks. It exhibits good levels of internal consistency, convergent and known-groups validity as well as test-retest reliability, even if patients with different angioedema conditions (chronic spontaneous urticaria, C1-INH-HAE, idiopathic angioedema) participated in its development [79]. AE-QoL scores were found to correlate well with DLQI, SF-36, and SF-12 scores, and with disease activity $[80,83]$. In addition, AE-QoL is also sensitive to changes, with a Minimal Clinically Important Difference (MCID) of six points [80]. The AE-QoL total score seems to be linked to angioedema attack rates; however, at an angioedema frequency of more

Table 2 Quality-of-life specific instruments in patients with hereditary angioedema

\begin{tabular}{|c|c|c|c|c|c|}
\hline QoL specific tool & References [PMID] & $\begin{array}{l}\text { Total no. } \\
\text { items }\end{array}$ & Recall period & Domains & Points \\
\hline AE-Qol & $\begin{array}{l}\text { Weller et al. [79] } \\
\text { [22913638] } \\
\text { Validated for angioedema (AE) as a symptom } \\
\text { and not for C1-INH-HAE }\end{array}$ & 17 & Last 4 weeks & $\begin{array}{l}\text { 1. Functioning } \\
\text { 2. Fatigue/mood } \\
\text { 3. Fears/shame } \\
\text { 4. Food }\end{array}$ & $0-100$ \\
\hline HAE-QOl & $\begin{array}{l}\text { Prior et al. [87] } \\
\text { [22817696]; Prior et al. [88] [26969268] } \\
\text { Validated for hereditary angioedema (HAE) }\end{array}$ & 25 & Last 6 months & $\begin{array}{l}\text { 1. Physical functioning and } \\
\text { health } \\
\text { 2. Role emotional and } \\
\text { social functioning } \\
\text { 3. Concern about offspring } \\
\text { 4. Treatment difficulties } \\
\text { 5. Disease-related stigma } \\
\text { 6. Perceived control over } \\
\text { illness } \\
\text { 7. Mental Health }\end{array}$ & $25-135$ \\
\hline
\end{tabular}


than four attacks per 4 weeks, the AE-QoL total score increase flattens, suggesting that the angioedema-related QoL impairment reaches a plateau when the number of attacks exceeds a critical rate [79]. AE-QoL is the recommended tool for assessing QoL in urticaria patients with angioedema in the EAACI/GA2LEN/EDF/WAO guidelines for urticaria [84-86]. As it is symptom-specific rather than disease-specific, AE-QoL does not include hereditary transmission but comprises "food", which is not a common trigger for HAE attacks.

\section{HAE-QoL}

The HAE-QoL draft version was carried out in a multicenter study in Spain performed in 2012 and thereafter internationalized in 2016, in a cross-cultural adaptation with 17 participating countries $[87,88]$. It consists of 25 items, grouped into seven HRQoL domains for C1-INHHAE adult patients, with a 6-month recall period [88]. The HAE-QoL has been developed following a qualitative methodology, considering the patient-centered perspective as a key issue to evaluate when assessing HRQoL [87]. After the international pilot study, HAEQoL showed good internal consistency and test-retest reliability, as well as a good discriminant validity in the psychometric analysis [88]. An American version, the United States HAE Association (HAEA)-QoL, based on the experiences and expectations of management of US patients, was developed in 2018 [89]. Additional validation studies and assessment of reliability to measure its ability to detect changes over time are ongoing [89].

\section{Impact of treatment on QoL in patients with hereditary angioedema}

Despite its efficacy, the therapy to be used in acute phases, given the high risk of potentially fatal outcomes of each attack, has no remarkable impact on the psychological aspects of this condition. The QoL of patients affected by HAE greatly depends on prophylactic therapies. Injection of C1-INH, recombinant or obtained from plasma of donors, is one of the most used options in this field. As shown in several studies, C1-INH therapy significantly improved the QoL scores, in comparison with placebo [90-92]. Lanadelumab, a monoclonal antibody acting as inhibitor of active plasma kallikrein [93], has been recently added among therapeutic strategies for long-term prophylaxis in patients aged $\geq 12$ years with HAE due to C1-INH-HAE [94]. The HELP study, a randomized double-blind placebo-controlled parallel-arm phase III study, other than demonstrating the efficacy of lanadelumab in reducing HAE attacks [95], investigated the effect of this biologic on patients' HRQoL [75]. During the treatment period, a greater proportion of lanadelumab-treated patients than placebo-treated patients achieved the favorable MCID in AE-QoL scores, and, among all domains, the largest improvement was recorded in functioning, indicating fewer restrictions in work, physical activity, leisure time and social relations. Positive results of lanadelumab on HRQoL were also confirmed in the open-label extension of the HELP study (HELP-OLE), with reduction in all domain scores, particularly in fears/shame (emotional burden) followed by functioning $[96,97]$. Another, smaller study prospectively assessed QoL in 12 adult HAE patients undergoing lanadelumab therapy for six months: a significant improvement was observed in all cases, together with significant reduction in the number of attacks [98].

Although further evidence is necessary, these data demonstrate that lanadelumab can dramatically improve QoL in patients with C1-INH-HAE, overcoming some limits of existing long-term prophylactic drugs such as adverse effects [99], need for frequent intravenous administrations [76], and sometimes limited availability, due to a shortage in supply (particularly in the case of plasma derived products) [100]. Moreover, a gradual extension of intervals between lanadelumab injections may be achieved without losing therapeutic efficacy, reducing the still high costs and furthering the idea of an individualized therapy [101].

\section{Quality of life in patients with cutaneous mastocytosis}

Mastocytosis is a rare disease characterized by the abnormal proliferation of clonal mast cells (MC) in various organs. In most cases, the disease is due to a gainof-function mutation of the KIT gene, encoding for the most important receptor on MC surface, regulating survival and proliferation of MC. The WHO classification of mastocytosis, recently updated, identifies two groups of disorders: cutaneous mastocytosis $(\mathrm{CM})$ and systemic mastocytosis (SM) [102, 103]. CM is usually diagnosed during childhood and involves only the skin, with a good prognosis and a general tendency to spontaneous resolution during puberty. On the other hand, SM is usually observed in adult patients and may involve different organs other than the skin, most frequently the bone marrow. Several variants of SM have been currently identified, ranging from Indolent Systemic Mastocytosis (ISM) with an excellent prognosis and an almost normal life expectancy, to Advanced Systemic Mastocytosis (AdvSM), with less favorable outcomes [102, 103]. The clinical picture depends either on the MC-organ infiltration or on mediator-related symptoms, including urticaria, flushing, pruritus, gastrointestinal symptoms (such as chronic diarrhea), fatigue and recurrent anaphylaxis. To measure and monitor the burden of symptoms in patients with mastocytosis, two main tools have been proposed, including the Mastocytosis Activity Score 
(MAS) [104] whose only limitation is the low percentage of patients with advanced disease participating to the validation study, and the Mastocytosis Symptoms Assessment Form (MSAF) also useful to monitor the effects of treatments in patients with SM (Table 3) [105]. However, although the clinical presentation of the disease is quite heterogeneous, general symptoms may deeply affect the QoL of patients, regardless of the severity of the disease and other parameters such as KIT mutation and tryptase levels [105-109]. Therefore, patients affected by all forms of mastocytosis largely share everyday difficulties and problems, starting from a generally relevant delay in the diagnosis. Jennings et al., reported indeed that the years occurring between the first symptoms and the final diagnosis ranged from less than 1 year to 50 years, with an average of 6.5 years [110]. However, a consistent delay in the diagnosis not only postpones the beginning of a correct multidisciplinary evaluation, but it also affects patients' global QoL. A quality study in 2019 demonstrated indeed that a correct diagnosis improves patients' QoL by giving them the opportunity of following appropriate therapies as well as of better understanding and accepting their disease [110]. Moreover, typical skin lesions are very frequent in patients with ISM and represent a relevant aesthetic problem for almost all patients, as they report not to feel comfortable in public places where people can look at them [108-110]. Skin lesions and pruritus seem indeed to be the most disabling symptoms, together with the risk for recurrent anaphylaxis [108-110]. A recent study conducted on 101 adult patients with mastocytosis shows that one third of patients felt moderately or severely impaired in QoL. Moreover, according to these Authors several factors may negatively influence the QoL, including food intolerance, osteoporosis, and the need for pharmacological treatments. Therefore, patients with anaphylaxis had a total MastoCytosis Quality of Life Questionnaire (MC-QoL) score only slightly more elevated than the one scored by patients without this manifestation, although this difference was not statistically significant. Interestingly, in this study, higher serum tryptase levels and a longer duration of symptoms were associated with higher QoL impairment [111].

\section{Cutaneous mastocytosis-specific QoL tools}

In 2016, two specific QoL questionnaires (MC-QoL and MQLQ) were developed [105, 112]. The MC-QoL explores 4 domains, including symptoms, emotions, social/life functioning, and skin, while the MQLQ focuses upon fatigue and mental health, anaphylaxis, skin symptoms, bone symptoms, and possible triggers (Table 3). Interestingly, although affecting a relatively low percentage of patients compared to other symptoms such as itching or fatigue, recurrent anaphylaxis shows a relevant impact on patients' QoL with a Mean Importance (MI), defined as the mean of all values given by patients

Table 3 Quality-of-life specific instruments in patients with mastocytosis

\begin{tabular}{|c|c|c|c|c|c|}
\hline QoL specific tool & References [PMID] & Total no. items & Recall Period & Domains & Points \\
\hline $\begin{array}{l}\text { MastoCytosis Quality } \\
\text { of Life Questionnaire } \\
\text { (MC-QoL) }\end{array}$ & $\begin{array}{l}\text { Siebenhaar et al. [112] } \\
\text { [26797792] }\end{array}$ & $\begin{array}{l}27 \text { items designed as } 5 \\
\text { points Likert scale }\end{array}$ & Last 2 weeks & $\begin{array}{l}\text { 1. Symptoms } \\
\text { 2. Emotions } \\
\text { 3. Social life/function- } \\
\text { ing } \\
\text { 4. Skin }\end{array}$ & $\begin{array}{l}0-108 \text { total points } \\
\text { Self-rated QoL impair- } \\
\text { ment cut-off } \\
29 \text { points: mild } \\
50 \text { points: moderate } \\
71 \text { points: severe }\end{array}$ \\
\hline $\begin{array}{l}\text { Mastocytosis Quality } \\
\text { of Life Questionnaire } \\
\text { (MQLQ) }\end{array}$ & $\begin{array}{l}\text { Van Anrooij et al. [105] } \\
\text { [27089859] }\end{array}$ & $\begin{array}{l}49 \text { items designed as } 0 \\
\text { to } 6 \text { points scale }\end{array}$ & $\begin{array}{l}\text { No specific evaluation } \\
\text { time frame }\end{array}$ & $\begin{array}{l}\text { 1. Fatigue and mental } \\
\text { health } \\
\text { 2. Anaphylaxis } \\
\text { 3. Skin symptoms } \\
\text { 4. Bone symptoms } \\
\text { 5. Un-familiarity } \\
\text { 6. Flushing } \\
\text { 7. General symptoms } \\
\text { 8. Triggers }\end{array}$ & $\begin{array}{l}\text { 0-294 total points } \\
\text { Cut-off not defined }\end{array}$ \\
\hline $\begin{array}{l}\text { Mastocytosis Symptom } \\
\text { Assessment Form } \\
\text { (MSAF) }\end{array}$ & $\begin{array}{l}\text { Van Anrooij et al. [105] } \\
\text { [27089859] }\end{array}$ & $\begin{array}{l}20 \text { items designed as } 0 \\
\text { to } 10 \text { points scale }\end{array}$ & $\begin{array}{l}\text { No specific evaluation } \\
\text { time frame }\end{array}$ & $\begin{array}{l}\text { 1. Severity of symp- } \\
\text { toms } \\
\text { 2. Impact of fatigue on } \\
\text { daily functioning }\end{array}$ & $\begin{array}{l}\text { 0-200 total points } \\
\text { Cut-off not defined }\end{array}$ \\
\hline $\begin{array}{l}\text { Mastocytosis Activity } \\
\text { Score (MAS) }\end{array}$ & $\begin{array}{l}\text { Siebenhaar et al. [104] } \\
\text { [29405310] }\end{array}$ & $\begin{array}{l}9 \text { items } \\
\text { designed as } 0 \text { to } 5 \\
\text { scale }\end{array}$ & $\begin{array}{l}\text { Daily-evaluation of the } \\
\text { last week }\end{array}$ & $\begin{array}{l}\text { 1. Skin symptoms } \\
\text { 2. Gastrointestinal } \\
\text { symptoms } \\
\text { 3. Others }\end{array}$ & $\begin{array}{l}0-252 \text { total points } \\
\text { Self-rated overall disease } \\
\text { severity cut-off } \\
11 \text { points: mild } \\
28.1 \text { points: moderate } \\
41.4 \text { points: severe }\end{array}$ \\
\hline
\end{tabular}


to each item according to the burden it displays on everyday life, of 3.39 according to the MC-QoL (range: 2.203.51), and 2.8 according to the MQLQ (range: 0-6) [105, $107,108,112,113]$. Moreover, recent studies are investigating the potential relationship between mastocytosis and psychological comorbidities [106, 114]. Vermeiren et al. [106], indeed, asked a total of 50 patients affected by either cutaneous or systemic mastocytosis to answer the questions of two different questionnaires (90-Item Symptom Checklist $=$ SCL-90 and 36 Item Short-Form Health Survey $=$ SF-36) exploring wide-spectrum psychological functions [106]. Surprisingly, according to SCL-90, mastocytosis patients reported lower scores compared to the general population in different categories such as depression, somatization, sleep disorders and inadequacy of acting and thinking, while scoring generally better than people suffering from chronic pain [106]. However, when answering the SF-36 questions, mastocytosis patients appeared to perceive worse body pain than cancer patients, also gaining comparable results regarding vitality and global health status awareness [106]. Interestingly, no differences were found between patients affected by cutaneous forms of mastocytosis and patients affected by systemic ones, thus underling once more how the impact on patients' QoL does not directly depend on the severity of the disease [106]. However, even if psychological impairment may be a direct consequence of the impact of the disease on the QoL, several Authors believe that depression may be a specific and molecular-based symptom of the disease, related to the constitutional MC activation, which seems to induce the hyperactivation of the indoleamine-2,3-dioxygenase enzyme, thus both enhancing the conversion of tryptophan into kynurenine and reducing its conversion into serotonin [114].

\section{Impact of treatment on QoL in patients with cutaneous mastocytosis}

In order to address the unmet needs of patients, several drugs, including both traditional ones such as rupatadine and more innovative ones such as omalizumab and midostaurin, have been administered to improve patients' QoL with encouraging results [115-118]. Rupatadine indeed was proved to be effective in reducing all mastocytosis-related symptoms, improving pruritus and decreasing the need for emergency drugs in 30 patients affected by mastocytosis (23 systemic and 7 cutaneous), when compared to placebo [115]. Moreover, in a study involving 116 patients affected by either cutaneous or systemic mastocytosis, midostaurin has been related to a significant improvement of the SF-12 and Memorial Symptom Assessment Scale scores, with a stable maintenance of the total scores for at least 36 months of follow up [116]. Omalizumab is a therapeutic tool that can be used off-label in patients with recurrent mediator-related symptoms not adequately controlled with the standard of care. Therefore, a recent systematic review of the literature demonstrated that omalizumab can drastically improve the typical symptoms of the disease with a first clinical response after 2.3 months (range: 1-6 months) [117]. However, only one study directly assessed the impact that omalizumab can have on patients' QoL, thus demonstrating a significant improvement of the Visual Analogue Scale (VAS) score from a basal average score of 8 to a final average score of 2 at last follow up [118]. However, although an increasing interest in mastocytosis patients' QoL is emerging from the current literature, all studies deal with adult patients with almost no references to the impact of the disease on pediatric patients as well as on their families. Only one study focused indeed upon the impact of UP on the QoL of 37 pediatric patients, reporting episodes of bullying and teasing in 15 patients as well as a general feeling of embarrassment in 12 patients [113]. For these reasons, more studies are needed to focus upon these aspects, also considering that, even if in pediatric patients mastocytosis is usually exclusively cutaneous and indolent, the general QoL does not strictly reflect the severity of the disease [109].

\section{Quality of life in patients with urticaria}

Urticaria is a heterogeneous group of disorders affecting skin and mucosal tissues characterized by the rapid occurrence of wheals, angioedema or both, the latter defining the urticaria-angioedema syndrome. The wheal is a skin lesion presenting with a central edema of variable size, surrounded by erythema, and associated with itching or, more rarely, feeling of warmth, that are transient, with spontaneous resolution in less than $24 \mathrm{~h}$, and with no relics. Classification of urticaria is based on duration of clinical manifestations and on causative agents [119]. Acute urticaria is defined by a duration of symptoms less than 6 weeks, while for chronic urticaria (CU) recurrent appearance of itchy wheals, angioedema, or both lasts more than 6 weeks. It is estimated that $12-22 \%$ of the population has suffered at least one subtype of urticaria during life [120], but only a small percentage (estimated at 7.6-16\%) has acute urticaria (AU), while the chronic urticaria affects a considerable part of the population worldwide with overall lifetime and point prevalence rates of $1.4 \%$ and $0.7 \%$, respectively [120]. The AU has a limited impact on the patient's life, otherwise the burden of CU for patients, their family and friends, the healthcare system and society is substantial [121]. Previously, O'Donnell et al. showed that health status scores in CU patients are comparable to those reported by patients with coronary artery disease [122]. There are several validated questionnaires helping to better define 
the burden of disease on patient's life as the CU quality of life questionnaire (CU-Q2oL), the urticaria activity score (UAS), the urticaria control test (UCT), the angioedema activity score (AAS), the AE-QoL and the DLQI [121, 123-127]. Improving the QoL in patients with CU is of the outmost importance, because this disease has a very great impact on patients' life, in terms of both duration and comorbidity. Omalizumab improves significantly patients' QoL, even if larger and standardized prospective studies are needed for better evaluation. Moreover, it should be evaluated the impact on QoL of the new available drugs to have a different therapeutic choice in case antihistamines or omalizumab could not be available or effective.

\section{Urticaria-specific QoL tools}

UAS, AAS and UCT are indicated to monitor disease control, while the CU-Q2oL, AE-QoL and DLQI are used to evaluate QoL impairment. These questionnaires are very useful, even if they are not always applicable in the daily clinical practice of patients with CU. The available data indicate that urticaria markedly interfered with sleep and daily activities. More than $20 \%$ of patients reported $\geq 1 \mathrm{~h}$ per week of missed work and the productivity impairment was $27 \%$. These effects increased with increasing disease activity. Furthermore, patients are concerned about the disabling effects and the stigma related to the appearance of angioedema or urticaria and this increases the burden of the disease. Therefore, the efficacy of CU treatment has a significant impact on patients' QoL and, consequently, on healthcare resources and costs [128].

\section{Impact of treatment on QoL in patients with urticaria}

The treatment of $\mathrm{CU}$ is characterized by a stepwise approach in which second-generation $\mathrm{H} 1$-antihistamines are the first-line medication for the initial management, according to the updated version of the EAACI/GA ${ }^{2} \mathrm{LEN} /$ EDF/WAO guidelines [86]. Second-generation H1-antihistamines have been preferred over the first-generation antihistamines for their better safety and efficacy profile, and their less sedative adverse effects. Continuous administration of antihistamines at standard dose is required, increasing up to four times the licensed dose (off-label use), as second line treatment, if symptoms are not adequately controlled after 2 to 4 weeks or earlier if the symptoms are intolerable. The major inconveniences for patients suffering from $\mathrm{CU}$ is firstly, the long duration of the disease (around two to five years) which therefore requires prolonged therapies with antihistamines, and secondly, the fact that the treatment's adherence tends to decrease over time because some patients discontinue medications when $\mathrm{CU}$ is asymptomatic $[129,130]$.
Moreover, most patients do not respond to the standard antihistamine dose, and they need an up-dosing, as reported in a recent observational study where $82 \%$ of patients did not respond to standard-dosed against 26\% of non-responding if higher doses of antihistamines were administered [131]. A systematic review showed that up dosing antihistamines significantly improves control of itching, but not weal number [132]. Unfortunately, some patients refuse to increase antihistamine dosage especially when it is higher than licensed dosage, because they are afraid of potential side effects, such as drowsiness, which can further contribute to a negative impact on QoL. More recently, efficacy and safety of up dosing of second generation $\mathrm{H} 1$-antihistamines has been reported. Most of the recent literature is focused on evaluation of bilastine, which showed a high safety profile with no interference with performance and learning abilities in both adults and children (age $\geq 6$ years old) improving QoL of patients suffering from urticaria [133]. A multicenter, randomized, double-blind, placebo-controlled study in Japanese population with CU showed the efficacy of bilastine compared to placebo, maintained up to 52 weeks in an open-label study $[134,135]$. Several studies have evaluated possible interactions of bilastine with daily activities and its influence on QoL. Demonte et al. evaluated the effect of 7 days treatment with $20 \mathrm{mg}$ daily bilastine on the driving ability rolling out possible interaction [136]. In a comparative study on a cohort of 58 adult patient affected by $\mathrm{CU}$, bilastine $20 \mathrm{mg}$ daily was found to be less-sedative and more effective long-term treatment compared to levocetirizine $5 \mathrm{mg}$ daily in term of UAS7 reduction at the end of treatment (UAS score mean change of $-31.6 \pm 1.5$ during bilastine $20 \mathrm{mg}$ therapy compared to mean change of $-27.4 \pm 1.7$ during levocetirizine $5 \mathrm{mg}$ daily), but with similar effect on improvement of QoL and urticarial-induced global discomfort in a follow-up period of 42 days. Both drugs statistically improved patients' QoL with comparable results: $94,8 \%$ of patients reported large to very large effect of chronic spontaneous urticaria (CSU) on QoL (DLQI score 11-30) in contrast to $8.6 \%$ of patient who referred small to moderate impairment of their QoL (DLQI $0-10)$ at the end of the study. In addition, longterm administration of levocetirizine $5 \mathrm{mg}$ daily was associated with greater onset of somnolence compared to bilastine $20 \mathrm{mg}$ daily (63\% Vs $12.9 \%$ ) [137]. Interestingly, significantly clinical improvement with bilastine compared to levocetirizine was observed only after 6 weeks of treatment (42 days) while it was comparable after 14 and 28 days in accordance with the findings of Zuberbier et al. reporting after 28 days of treatment changes in DLQI and UAS scores [138]. Omalizumab is the first non-antihistamine drug licensed for the treatment of 
$\mathrm{CSU}$, as third line treatment, according to international guidelines [86]. Approved for the treatment of antihistamine-resistant CSU in patients 12 years or older $(300 \mathrm{mg}$ subcutaneous every 4 weeks), omalizumab has been proved to be safe and effective in several randomized controlled trials $[139,140]$ and several real-world studies [141, 142], as well as to improve QoL in CSU patients [143]. There are many questionnaires to evaluate the effect of omalizumab on quality of life, but the most utilized in registration studies was DLQI. In the studies ASTERIA I, ASTERIA II and GLACIAL omalizumab $300 \mathrm{mg}$ every 4 weeks significantly improved the total DLQI scores compared to placebo $(p<0.01$; all studies) [144]. According to a recent EAACI's review on the effectiveness and safety of omalizumab, the normal dosage of $300 \mathrm{mg}$ q4w improved QoL reducing at the same time the DLQI in 6 RCTs and the CU-Q2ol in 3 RCTs compared to standard of care [145]. The clinical benefits associated with omalizumab therapy in real-world management of CSU are less known. A meta-analysis of 67 studies, assessing the real-world effectiveness of omalizumab in CSU (with or without angioedema), showed a significant QoL improvement in patients treated with omalizumab with a reduction of the DLQI score (13.9 points) in 6 studies involving 84 patients and a reduction of $\mathrm{CU}$ Q2oL (42.3 points) in 3 studies involving 70 patients [146]. In a systematic review of 84 publications, Bernstein et al. reported the real-world effectiveness of omalizumab for treatment of CSU. QoL outcomes improved by $76.2 \%$ (DLQI; 6 studies and 70 patients) and 71.1\% (CU-Q2oL; 5 studies and 72 patients) [147]. There is an increasing number of real-world studies that evaluate the effectiveness of the up dosing of omalizumab in CSU (450 mg o $600 \mathrm{mg} \mathrm{q} 4 \mathrm{w}$ ), proving improvements in UAS7, UCT, and quality of life scores in patients who were not responding sufficiently to standard dose of omalizumab [148]. Some RCTs proved the efficacy of omalizumab in CSU patients with angioedema, associated symptom in $33-67 \%$ of patients [149], resulting in an improvement of the frequency and the severity of the angioedema itself (ASS) and the QoL (AEQoL) $[150,151]$. In the RCTs X-ACT, that included only CSU patients who have had 4 or more angioedema episodes at timeline 0 , treatment with omalizumab $300 \mathrm{mg}$ q4w for 28 weeks significantly decreased the AAS and AE-QoL, with evident improvements already in the first 4 weeks [152]. Maurer et al. showed that patients treated with omalizumab $300 \mathrm{mg}$ had more clinical benefits, in terms of QoL improvement and reduction of the frequency of the angioedema episodes, as compared to patients treated with omalizumab $150 \mathrm{mg}$ or $75 \mathrm{mg}$ [153]. To date, no RCT has included CSU patients that suffer from recurrent angioedema without wheals. Some case reports document an improvement of
ASS and AE-QoL in individuals after omalizumab treatment [154]. Ciclosporin is an off-label drug for urticarial recommended by 2021 international guideline as fourline treatment in patients not responding to omalizumab in combination with antihistamines treatment [86]. It directly inhibits mast cell degranulation in a moderate way as well as targeting $\mathrm{T}$ cells involved in pathogenetic mechanisms of urticaria. Although effective, its use is limited by several potential adverse effects such as hypertension, nephrotoxicity, headache, nausea, and gastrointestinal problems [155-157]. A close monitoring of blood pressure and renal function is needed in patients who are taking ciclosporin for $\mathrm{CU}$ resulting in considerable discomfort for patients that further impaired their QoL, even if the longer the duration of use, the higher the risk of side effects. There are few studies regarding ciclosporin and QoL in patients with urticaria. Two parallel multicenter retrospective observational studies [158] have compared outcomes and change of DLQI in patients treated with omalizumab or cyclosporin highlighting a greater improvement in mean DLQI in patient treated with omalizumab than ciclosporin $(75 \%$ reduction in DLQI was achieved in $79 \%$ and $41 \%$, respectively; while $90 \%$ reduction in DLQI was achieved in 65 and 18\%, respectively). As bias of the study, DLQI was subjected only to a minority of patients examined. Clinical outcomes of patients treated with ciclosporin (dosage $3-4 \mathrm{mg} / \mathrm{kg} / \mathrm{die}$ ) were not evaluated through UAS7 score and clinical remission was achieved only in $17 \%$ (vs omalizumab treatment $42 \%$ ), clinical improvement in 55\% while no response in $28 \%$ of patients. Several novel treatments for CU are currently under development [159]. Ligelizumab is a high affinity humanized monoclonal anti-IgE antibody. In the phase $2 \mathrm{~b}$ dose-finding trial, a superior efficacy and persistent response, in terms of both UAS7 and AAS scores, was observed in patients treated with ligelizumab compared with the omalizumab group [160]. Other biologics, already approved for the treatment of $\mathrm{AD}$ and/or asthma and/or chronic rhinosinusitis with nasal polyposis, could be off-label used in CU. Lee and Simpson evaluate UAS at baseline and 3 months after dupilumab in 6 patients affected by both $\mathrm{AD}$ and $\mathrm{CU}$, unresponsive to omalizumab, with good results [161]. There are two ongoing RCTs to estimate efficacy and safety of dupilumab in CU. Several case reports of mepolizumab, reslizumab and benralizumab, used to treat $\mathrm{CU}$ occurred in asthma patients, suggest that blocking of IL- 5 axis could be a promising option [159]. Maurer et al. described a sudden improvement of symptoms and QoL of a patient with CU and cold urticaria with UCT score of 16 four weeks after the first injection of reslizumab, indicating complete disease control. This score was maintained for at least four months 
after treatment [162]. There is no further available data about QoL for these treatments yet.

\section{Conclusions}

Allergic and immunologic skin diseases have a significant impact on patients' QoL. Physicians diagnose diseases to care for and cure patients. The assessment of QoL is important for clinical decision and relies on questionnaires which are answered directly by the patient, thus QoL is indeed in the eye of the beholder. As Sir William Osler stated in Aequinimitas more than a century ago, the value of experience is in seeing wisely, in this case, balancing efforts in treating disease with the burden of the illness in a patient's life.

\begin{abstract}
Abbreviations
AAS: Angioedema activity score; ACD: Allergic contact dermatitis; AD: Atopic dermatitis; ADvSM: Advanced Systemic Mastocytosis; AE: Angioedema; AE-QoL: Angioedema quality of life questionnaire; AU: Acute urticaria; CADIS: Childhood Atopic Dermatitis Impact Scale; CD: Contact dermatitis; CDLQI: Children's Dermatology Life Quality Index; CM: Cutaneous mastocytosis; CU: Chronic urticaria; CU-Q2oL: CU quality of life questionnaire; C1-INH: C1 esterase inhibitor; DLQI: Dermatology Life Quality Index; DSQL: DermatologySpecific Quality of Life; EQ-5D: EuroQol-5D; EQ VAS: EuroQol visual analogue scale; FQLI: Fragrance Quality of Life Index; HAE: Hereditary angioedema; HAEA-QoL: The United States HAE Association QoL questionnaire; HAE-QoL: Hereditary Angioedema QoL questionnaire; HRQoL: Health Related Quality of Life; ICD: Irritant contact dermatitis; ISM: Indolent Systemic Mastocytosis; MAS: Mastocytosis activity score; MC: Mast cells; MCID: Minimal clinically important difference; MC-QoL: MastoCytosis Quality of Life Questionnaire; MI: Mean importance; MQLQ: Mastocytosis Quality of Life Questionnaire; MSAF: Mastocytosis Symptoms Assessment Form; NHP: Nottingham Health Profile; NRS: Numerical Rating Scale; PUVA: Psoralen plus UVA; QoL: Quality of life; QOLHEQ: Quality of life in Hand Eczema Questionnaire; QoLIAD: QoL Index for Atopic Dermatitis; SCL-90: 90-Item Symptom Checklist; SF-12: Short Form 12 Health Survey; SF-36: Short Form 36 Health Survey; SIAAIC: Italian Society of Allergology, Asthma and Clinical Immunology; SIDAPA: Italian Society of Allergological, Occupational and Enviromental Dermatology; SM: Systemic mastocytosis; UAS: Urticaria activity score; UCT: Urticaria control test; WPAl: Work Productivity and Activity Impairment.
\end{abstract}

\section{Acknowledgements}

None.

\section{Authors' contributions}

OR, EN, MC, IB, EDA, LS designed and conceptualized the final manuscript. All Authors reviewed the literature and contributed to the writing of the manuscript. Meeting moderators were IB, MC, EN, OR. Document on quality of life in patients with atopic dermatitis was written by EDL, CF, DP, LS, FA, EA, $R B, L G$. Document on quality of life in patients with allergic contact dermatitis was written by MC, AD, KH, PM, FB, LS, NS, MT. Document on quality of life in patients with hereditary angioedema/patients affected by skin diseases and treated with biological therapies was written by $L B, F G, C P, G S, P C, E D A, A G$, IP. Document on quality of life in patients with cutaneous mastocytosis was written by ADM, ADG, RP, DT, DB, MN, CL, FF. Document on quality of life in patients with urticaria was written by SF, RG, CQ, AP, MF, LA, DL, AP. All Authors read and approved the final version of the manuscript.

\section{Funding}

None.

Availability of data and materials Not applicable.

\section{Declarations}

Ethics approval and consent to participate Not applicable.

\section{Consent for publication}

Not applicable.

\section{Competing interests}

The authors declares that they have no competing interests.

\section{Author details}

${ }^{1}$ Department of Experimental and Clinical Medicine, University of Florence, Firenze, Italy. ${ }^{2}$ Section of Dermatology and Infectious Diseases, Department of Medical Sciences, University of Ferrara, Ferrara, Italy. ${ }^{3}$ Respiratory Unit for Continuity of Care, IRCCS Ospedale Policlinico San Martino, Department of Internal Medicine (DiMI), University of Genoa, Genova, Italy. ${ }^{4}$ Personalized Medicine, Asthma and Allergy, IRCCS Humanitas Research Hospital, Rozzano, Milano, Italy. ${ }^{5}$ Department of Biomedical Science and Human Oncology, Section of Dermatology, University of Bari, Bari, Italy. ${ }^{6}$ Dermatology Unit, Fondazione IRCCS Ca' Granda Ospedale Maggiore Policlinico, Milano, Italy. ${ }^{7}$ Section of Dermatology, Department of Medicine and Surgery, University of Perugia, Perugia, Italy. ${ }^{8}$ ASP Trapani, Trapani, Italy. ${ }^{9}$ Department of Biomedical Sciences and Human Oncology, Section of Dermatology, University of Bari, Bari, Italy. ${ }^{10}$ Dermatology Unit, Azienda USL - IRCCS di Reggio Emilia, Reggio Emilia, Italy. ${ }^{11}$ Division of Allergy and Clinical Immunology, "Santa Maria Della Speranza" Hospital, Salerno, Italy. ${ }^{12}$ Section of Dermatology, Department of Clinical and Experimental Medicine, University of Messina, Messina, Italy. ${ }^{13}$ Department of Internal Medicine, Clinical Immunology, Clinical Pathology and Infectious Disease, Azienda Ospedaliera Universitaria Federico II, Napoli, Italy. ${ }^{14}$ Section of Dermatology, Department of Clinical Medicine and Surgery, University of Naples Federico II, Napoli, Italy. ${ }^{15}$ Section of Allergy and Clinical Immunology, Unit of Internal Medicine-"F. Miulli" Hospital, Acquaviva Delle Fonti, Bari, Italy. ${ }^{16}$ Unit of Allergology, Department of Dermatology, Policlinico Umberto I, Hospital-University Sapienza of Rome, Roma, Italy. ${ }^{17}$ Allergy and Clinical Immunology Unit, San Giovanni di Dio Hospital, Firenze, Italy. ${ }^{18}$ Section of Dermatology - Department of Health Sciences, University of Genoa, Ospedale Policlinico San Martino - IRCCS, Genova, Italy. ${ }^{19}$ Department of Medicine and Science of Ageing, G. d'Annunzio University, Chieti, Italy. ${ }^{20}$ Allergy Unit, Department of Medicine, University of Verona, Verona, Italy. ${ }^{21}$ Allergy Unit, Villa Igea Hospital. A.P.S.S. Trento, Trento, Italy. ${ }^{22}$ Department of Clinical and Experimental Medicine, School and Division of Allergy and Clinical Immunology, University Hospital 'G. Martino', Messina, Italy. ${ }^{23}$ Department of Medicine and Health Science "V. Tiberio", University of Molise, Campobasso, Italy. ${ }^{24}$ Allergology and Immunology Clinic, Operative Unit of Medicine, Policoro Hospital, Policoro, Matera, Italy. ${ }^{25}$ Section of Dermatology, Department of Health Sciences, University of Genoa, Ospedale Policlinico San Martino - IRCCS, Genova, Italy. ${ }^{26}$ Department of Medicine, Division of Allergy and Clinical Immunology, University of Salerno, Salerno, Italy. ${ }^{27}$ Department of Health Sciences, University Magna Graecia of Catanzaro, Catanzaro, Italy. ${ }^{28}$ Section of Pediatrics, Department of Clinical and Experimental Medicine, University of Pisa, Pisa, Italy. ${ }^{29}$ Io e I'Asma Center, Children's Hospital, ASST Spedali Civili, Brescia, Italy. ${ }^{30}$ Department of Translational Medical Sciences and Center for Basic and Clinical Immunology Research (CISI), University of Naples Federico II, Napoli, Italy. ${ }^{31}$ Allergy and Clinical Immunology Unit, Department of Clinical Medicine, Mauriziano Umberto I Hospital, University of Turin, Torino, Italy. ${ }^{32}$ Department of Emergency and Organ Transplantation, School and Chair of Allergology and Clinical Immunology, University of Bari - Aldo Moro, Bari, Italy. ${ }^{33}$ Immunoallergology Unit, SOD Immunoallergologia, Azienda Ospedaliero-Universitaria Careggi, Firenze, Italy.

Received: 4 October 2021 Accepted: 15 November 2021

Published online: 20 December 2021

\author{
References \\ 1. Nettis E, Aloia AM, Di Leo E, D’Erasmo M, Calogiuri GF, Ferrannini \\ A, Vacca A. Qualità della vita nelle malattie cutanee d'interesse
}


allergologico [Quality of life in cutaneous diseases belonging to allergological field]. It J Allergy Clin Immunol. 2009;19:84-91 (in italian).

2. Wells GA, Russell AS, Haraoui B, Bissonnette R, Ware CF. Validity of quality of life measurement tools-from generic to disease-specific. J Rheumatol Suppl. 2011;88:2-6. https://doi.org/10.3899/jrheum.110906.

3. Jandhyala R. Neutral theory: applicability and neutrality of using generic health-related quality of life tools in diseases or conditions where specific tools are available. BMC Med Res Methodol. 2021;21(1):86. https://doi.org/10.1186/s12874-021-01279-w.

4. Both H, Essink-Bot ML, Busschbach J, Nijsten T. Critical review of generic and dermatology-specific healthrelated quality of life instruments. J Invest Dermatol. 2007;127:2726-39.

5. McHorney CA, Ware JE Jr, Raczek AE. The MOS 36-item Short- Form Health Survey (SF-36). II. Psychometric and clinical tests of validity in measuring physical and mental health constructs. Med Care. 1993;31:247-63.

6. Szende A, Janssen B, Cabases J, editors. Self-reported population health: an international perspective based on EQ-5D. Dordrecht (NL): Springer; 2014

7. Busija L, Pausenberger E, Haines TP, Haymes S, Buchbinder R, Osborne RH. Adult measures of general health and health-related quality of life: Medical Outcomes Study Short Form 36-Item (SF-36) and Short Form 12-Item (SF-12) Health Surveys, Nottingham Health Profile (NHP), Sickness Impact Profile (SIP), Medical Outcomes Study Short Form 6D (SF-6D), Health Utilities Index Mark 3 (HUI3), Quality of Well-Being Scale (QWB), and Assessment of Quality of Life (AQoL). Arthritis Care Res (Hoboken). 2011;63(Suppl 11):S383-412. https://doi.org/10.1002/acr. 20541.

8. Basra MKA, Fenech R, Gatt RM, et al. The Dermatology Life Quality Index 1994-2007: a comprehensive review of validation data and clinical results. Br J Dermatol. 2008:159:997-1035.

9. Anderson RT, Rajagopalan R. Development and validation of a quality of life instrument for cutaneous diseases. J Am Acad Dermatol. 1997;37(1):41-50. https://doi.org/10.1016/s0190-9622(97)70210-x.

10. Ratchataswan T, Banzon TM, Thyssen JP, Weidinger S, Guttman-Yassky E, Phipatanakul W. Biologics for treatment of atopic dermatitis: current status and future prospect. J Allergy Clin Immunol Pract. 2021;9(3):1053-65.

11. Mozaffari H, Pourpak Z, Pourseyed S, Farhoodi A, Aghamohammadi A, Movahadi A, et al. Quality of life in atopic dermatitis patients. J Microbiol Immunol Infect. 2007;50:260-5.

12. Carrol CL, Balkrishnam R, Feldam SR, Fleischer AB, Manuel JC. The burden of atopic dermatitis: impact on the patient, family, and society. Pediatr Dermatol. 2005;22:192-9.

13. Neri E, Agostini F, Gremigni P, Gobbi F, Casu G, Chamlin SL, Monti F. Italian validation of the Childhood Atopic Dermatitis Impact Scale: a contribution to its clinical application. J Invest Dermatol. 2012;132(11):2534-43. https://doi.org/10.1038/jid.2012.199 (Epub 2012 Jun 14)

14. Ricci G, Bendandi B, Bellini F, Patrizi A, Masi M. Atopic dermatitis: quality of life of young italian children and their families and correlation with severity score. Pediatr Allergy Immunol. 2007;18:255-9.

15. Kiebert G, Sorensen SV, Revicki D, Fagan SC, Doyle JJ, Cohen J, et al. Atopic dermatitis is associated with a decrement in health-related quality of life. Int J Dermatol. 2002;51:151-8.

16. Schmitt J, Williams H, HOME Development Group. Harmonising Outcome Measures for Eczema (HOME). Report from the First International Consensus Meeting (HOME 1), 24 July 2010, Munich, Germany. Br J Dermatol. 2010;163(6):1166-8. https://doi.org/10.1111/j.1365-2133. 2010.10054.x

17. Whalley D, McKenna SP, Dewar AL, Erdman RA, KohImann T, Niero M, et al. A new instrument for assessing quality of life in atopic dermatitis: international development of the Quality of Life Index for Atopic Dermatitis (QoLIAD). Br J Dermatol. 2005;150:275-83.

18. Sidbury R, Davis DM, Cohen DE, Cordoro KM, Berger TG, Bergman JN, Chamlin SL, Cooper KD, Feldman SR, Hanifin JM, Krol A, Margolis DJ, Paller AS, Schwarzenberger K, Silverman RA, Simpson EL, Tom WL, Williams HC, Elmets CA, Block J, Harrod CG, Begolka WS, Eichenfield LF, American Academy of Dermatology. Guidelines of care for the management of atopic dermatitis: section 3. Management and treatment with phototherapy and systemic agents. J Am Acad Dermatol. 2014;71(2):327 (Epub 2014 May 9).

19. Chu CY. Treatments for childhood atopic dermatitis: an update on emerging therapies. Clin Rev Allergy Immunol. 2020. https://doi.org/10. 1007/s12016-020-08799-1.

20. Simpson EL, Bieber T, Guttman-Yassky E, SOLO 1 and SOLO 2 investigators, et al. Two phase 3 trials of dupilumab versus placebo in atopic dermatitis. N Engl J Med. 2016;375(24):2335-48.

21. Silverberg Jl, Simpson EL, Ardeleanu M, et al. Dupilumab provides important clinical benefits to patients with atopic dermatitis who do not achieve clear or almost clear skin according to the Investigator's Global Assessment: a pooled analysis of data from two phase III trials. Br J Dermatol. 2019;181(1):80-7.

22. Wollenberg A, Beck LA, Blauvelt A, et al. Laboratory safety of dupilumab in moderate-to-severe atopic dermatitis: results from three phase III trials (LIBERTY AD SOLO 1, LIBERTY AD SOLO 2, LIBERTY AD CHRONOS). Br J Dermatol. 2020;182(5):1120-35.

23. Thaçi $D$, Simpson LE, Deleuran $M$, et al. Efficacy and safety of dupilumab monotherapy in adults with moderate-to-severe atopic dermatitis: a pooled analysis of two phase 3 randomized trials (LIBERTY AD SOLO 1 and LIBERTY AD SOLO 2). J Dermatol Sci. 2019;94(2):266-75.

24. Paller AS, Bansal A, Simpson EL, et al. A clinically meaningful responses to dupilumab in adolescents with uncontrolled moderate-to-severe atopic dermatitis: post-hoc analyses from a randomized clinical trial. Am J Clin Dermatol. 2020;21(1):119-31.

25. Patruno C, Napolitano M, Argenziano G, et al. Dupilumab therapy of atopic dermatitis of the elderly: a multicentre, real-life study. J Eur Acad Dermatol Venereol. 2021;35(4):958-64.

26. Nettis E, Ferrucci SM, Ortoncelli M, et al. Use of dupilumab for 543 adult patients with moderate-to-severe atopic dermatitis: a multicenter, retrospective study. J Investig Allergol Clin Immunol. 2020.

27. Czarnowicki T, He H, Krueger JG, Guttman-Yassky E. Atopic dermatitis endotypes and implications for targeted therapeutics. J Allergy Clin Immunol. 2019;143(1):1-11. https://doi.org/10.1016/j.jaci.2018.10.032.

28. Usatine RP, Riojas M. Diagnosis and management of contact dermatitis. Am Fam Physician. 2010;82(3):249-55.

29. Elmas ÖF, Akdeniz N, Atasoy M, Karadag AS. Contact dermatitis: a great imitator. Clin Dermatol. 2020;38(2):176-92. https://doi.org/10.1016/j. clindermatol.2019.10.003 (Epub 2019 Oct 24).

30. Bains SN, Nash P, Fonacier L. Irritant contact dermatitis. Clin Rev Allergy Immunol. 2019;56(1):99-109. https://doi.org/10.1007/ s12016-018-8713-0.

31. Nassau S, Fonacier L. Allergic contact dermatitis. Med Clin North Am. 2020;104(1):61-76. https://doi.org/10.1016/j.mcna.2019.08.012 (Epub 2019 Oct 28)

32. Botto N, Raffi J, Trivedi M, Ramirez F, Allen IE, Chren MM. Validating a quality-of-life instrument for allergic contact dermatitis. Dermatitis. 2019;30(5):300-5. https://doi.org/10.1097/DER.0000000000000515.

33. Kadyk DL, McCarter K, Achen F, Belsito DV. Quality of life in patients with allergic contact dermatitis. J Am Acad Dermatol. 2003;49(6):1037-48. https://doi.org/10.1016/s0190-9622(03)02112-1.

34. Potocka A, Turczyn-Jabłońska K, Kieć-Swierczyńska M. Self-image and quality of life of dermatology patients. Int J Occup Med Environ Health. 2008;21(4):309-17. https://doi.org/10.2478/v10001-008-0034-8.

35. Raffi J, Elaine Allen I, Botto N. Validating responsiveness of a quality-of-life instrument for allergic contact dermatitis. Dermatitis. 2020;31(3):209-14. https://doi.org/10.1097/DER.0000000000000542.

36. Rocholl M, Ludewig M, Brakemeier C, John SM, Wilke A. Illness perceptions of adults with eczematous skin diseases: a systematic mixed studies review. Syst Rev. 2021;10(1):141. https://doi.org/10.1186/ s13643-021-01687-5.

37. Swietlik J, Reeder M. Current quality-of-life tools available for use in contact dermatitis. Dermatitis. 2016;27(4):176-85. https://doi.org/10. 1097/DER.0000000000000192

38. Ayala F, Nino M, Fabbrocini G, Panariello L, Balato N, Foti C, Tosti A, Corazza M, Valsecchi RH, Gola M, Gallo R, Guarneri F, Pigatto PD, Cristaudo A, Schena D, Musumeci ML, Stingeni L, Lisi P. Quality of life and contact dermatitis: a disease-specific questionnaire. Dermatitis. 2010;21(2):84-90

39. Kalboussi H, Kacem I, Aroui H, El Maalel O, Maoua M, Brahem A, El Guedri S, Chatti S, Ghariani N, Mrizak N. Impact of allergic contact 
dermatitis on the quality of life and work productivity. Dermatol Res Pract. 2019;2019:3797536. https://doi.org/10.1155/2019/3797536.

40. Potocka A, Turczyn-Jabloñska K, Merecz D. Psychological correlates of quality of life in dermatology patients: the role of mental health and self-acceptance. Acta Dermatovenerol Alp Pannonica Adriat. 2009;18(2):53-62.

41. Ofenloch RF, Weisshaar E, Dumke AK, Molin S, Diepgen TL, Apfelbacher C. The Quality of Life in Hand Eczema Questionnaire (QOLHEQ): validation of the German version of a new disease-specific measure of quality of life for patients with hand eczema. Br J Dermatol. 2014;171(2):30412. https://doi.org/10.1111/bjd.12819 (Epub 2014 Jun 18)

42. Stingeni L, Bianchi L, Hansel K, Corazza M, Gallo R, Guarneri F, Patruno C, Rigano L, Romita P, Pigatto PD, Calzavara-Pinton P; "Skin Allergy" group of SIDeMaST and "SIDAPA" (Società Italiana di Dermatologia Allergologica, Professionale e Ambientale). Italian Guidelines in Patch Testing adapted from the European Society of Contact Dermatitis (ESCD). G Ital Dermatol Venereol. 2019;154(3):227-253. doi: https://doi.org/10.23736/ S0392-0488.19.06301-6. Epub 2019 Feb 4.

43. Kadyk DL, Hall S, Belsito DV. Quality of life of patients with allergic contact dermatitis: an exploratory analysis by gender, ethnicity, age, and occupation. Dermatitis. 2004;15(3):117-24. https://doi.org/10.2310/ 6620.2004.04007.

44. Rajagopalan R, Anderson RT, Sarma S, Kallal J, Retchin C, Jones J, Fowler JF Jr, Sherertz EF. An economic evaluation of patch testing in the diagnosis and management of allergic contact dermatitis. Am J Contact Dermat. 1998;9(3):149-54.

45. Ramirez F, Chren MM, Botto N. A review of the impact of patch testing on quality of life in allergic contact dermatitis. J Am Acad Dermatol. 2017;76(5):1000-4. https://doi.org/10.1016/j.jaad.2016.12.011.

46. Thomson KF, Wilkinson SM, Sommer S, Pollock B. Eczema: quality of life by body site and the effect of patch testing. $\mathrm{Br} J$ Dermatol. 2002;146(4):627-30. https://doi.org/10.1046/j.1365-2133.2002.04692.x.

47. Woo PN, Hay IC, Ormerod AD. An audit of the value of patch testing and its effect on quality of life. Contact Dermatitis. 2003;48(5):244-7. https://doi.org/10.1034/j.1600-0536.2003.00113.x.

48. Skoet $\mathrm{R}$, Zachariae R, Agner T. Contact dermatitis and quality of life: a structured review of the literature. Br J Dermatol. 2003;149(3):452-6. https://doi.org/10.1046/j.1365-2133.2003.05601.x.

49. Both H, Essink-Bot ML, Busschbach J, Nijsten T. Critical review of generic and dermatology-specific health-related quality of life instruments. J Invest Dermatol. 2007;127(12):2726-39. https://doi.org/10.1038/sj.jid. 5701142 (Epub 2007 Nov 8).

50. Braunberger T, Lynn D, Reimer C, Doctor M, Hill MK, Mounessa J, Dunnick CA. Disease severity and quality of life measurements in contact dermatitis: a systematic review 2005-2015. Dermatitis. 2016;27(6):36271. https://doi.org/10.1097/DER.0000000000000235.

51. Chernyshov PV. The evolution of quality of life assessment and use in dermatology. Dermatology. 2019;235(3):167-74. https://doi.org/10. 1159/000496923 (Epub 2019 Mar 29).

52. Chernyshov PV, John SM, Tomas-Aragones L, Gonçalo M, Svensson A, Bewley A, Evers AWM, Szepietowski JC, Marron SE, Manolache L, Pustisek N, Suru A, Salavastru CM, Tiplica GS, Salek MS, Finlay AY. Quality of life measurement in occupational skin diseases. Position paper of the European Academy of Dermatology and Venereology Task Forces on Quality of Life and Patient Oriented Outcomes and Occupational Skin Disease. J Eur Acad Dermatol Venereol. 2020;34(9):1924-31. https://doi. org/10.1111/jdv.16742 (Epub 2020 Jul 13).

53. Reilly MC, Lavin PT, Kahler KH, Pariser DM. Validation of the Dermatology Life Quality Index and the Work Productivity and Activity Impairment-Chronic Hand Dermatitis questionnaire in chronic hand dermatitis. J Am Acad Dermatol. 2003;48(1):128-30. https://doi.org/10. 1067/mjd.2003.128.

54. Lau MY, Matheson MC, Burgess JA, Dharmage SC, Nixon R. Disease severity and quality of life in a follow-up study of patients with occupational contact dermatitis. Contact Dermatitis. 2011;65(3):138-45. https://doi.org/10.1111/j.1600-0536.2011.01896.x (Epub 2011 Jul 3).

55. Matterne U, Apfelbacher CJ, Soder S, Diepgen TL, Weisshaar E. Healthrelated quality of life in health care workers with work-related skin diseases. Contact Dermatitis. 2009;61(3):145-51. https://doi.org/10. $1111 / \mathrm{j} .1600-0536.2009 .01592 . x$.
56. Rajagopalan R, Anderson R. Impact of patch testing on dermatologyspecific quality of life in patients with allergic contact dermatitis. Am J Contact Dermat. 1997;8(4):215-21.

57. Heisterberg MV, Menné T, Johansen JD. Fragrance allergy and quality of life-a case-control study. Contact Dermatitis. 2014;70(2):81-9. https:// doi.org/10.1111/cod.12128.

58. Heisterberg MV, Menné T, Johansen JD. Fragrance allergy and quality of life-development and validation of a disease-specific quality of life instrument. Contact Dermatitis. 2014;70(2):69-80.

59. Bennike NH, Heisterberg MS, White IR, Mahler V, Silvestre-Salvador JF, Giménez-Arnau A, Johansen JD. Quality of life and disease severity in dermatitis patients with fragrance allergy-A cross-sectional European questionnaire study. Contact Dermatitis. 2019;81(2):89-96. https://doi. org/10.1111/cod.13252 (Epub 2019 Apr 1).

60. Ofenloch RF, Oosterhaven JAF, Susitaival P, Svensson Å, Weisshaar E, Minamoto K, Onder M, Schuttelaar MLA, Bulbul Baskan E, Diepgen TL, Apfelbacher C. Cross-cultural validation of the quality of life in hand eczema questionnaire (QOLHEQ). J Invest Dermatol. 2017;137(7):145460. https://doi.org/10.1016/j.jid.2017.02.969 (Epub 2017 Mar 1).

61. Lau MY, Burgess JA, Nixon R, Dharmage SC, Matheson MC. A review of the impact of occupational contact dermatitis on quality of life. J Allergy (Cairo). 2011;2011: 964509. https://doi.org/10.1155/2011/ 964509 (Epub 2011 Mar 16).

62. Hutchings CV, Shum KW, Gawkrodger DJ. Occupational contact dermatitis has an appreciable impact on quality of life. Contact Dermatitis. 2001;45(1):17-20. https://doi.org/10.1034/j.1600-0536.2001.04500 1017.x.

63. Simonsen AB, Sommerlund M, Deleuran M, Mortz CG, Johansen JD. Course of skin symptoms and quality of life in children referred for patch testing--a long-term follow-up study. Acta Derm Venereol. 2015;95(2):206-10. https://doi.org/10.2340/00015555-1911. Erratum in: Acta Derm Venereol. 2015;95(6):767-8.

64. Scheinman PL, Vocanson M, Thyssen JP, Johansen JD, Nixon RL, Dear K, Botto NC, Morot J, Goldminz AM. Contact dermatitis. Nat Rev Dis Primers. 2021;7(1):38. https://doi.org/10.1038/s41572-021-00271-4.

65. Bhatia J, Sarin A, Wollina U, Lotti T, Navarini AA, Mueller SM, Grabbe S, Saloga J, Rokni GR, Goldust M. Review of biologics in allergic contact dermatitis. Contact Dermatitis. 2020;83(3):179-81. https://doi.org/10. 1111/cod.13584 (Epub 2020 Jun 17).

66. Cassano N, Loconsole F, Coviello C, Vena GA. Infliximab in recalcitrant severe atopic eczema associated with contact allergy. Int J Immunopathol Pharmacol. 2006;19(1):237-40.

67. Rosmarin D, Bush M, Scheinman PL. Patch testing a patient with allergic contact hand dermatitis who is taking infliximab. J Am Acad Dermatol. 2008;59(1):145-7. https://doi.org/10.1016/j.jaad.2008.02.016 (Epub 2008 May 12).

68. Joshi SR, Khan DA. Effective use of dupilumab in managing systemic allergic contact dermatitis. Dermatitis. 2018;29(5):282-4. https://doi. org/10.1097/DER.0000000000000409.

69. Machler BC, Sung CT, Darwin E, Jacob SE. Dupilumab use in allergic contact dermatitis. J Am Acad Dermatol. 2019;80(1):280-281.e1. https:// doi.org/10.1016/j.jaad.2018.07.043 (Epub 2018 Aug 6).

70. Mur Gimeno P, Martín Iglesias A, Lombardero Vega M, Bautista Martínez P, Ventura LP. Occupational wheat contact dermatitis and treatment with omalizumab. J Investig Allergol Clin Immunol. 2013;23(4):287-8.

71. Nguyen TG. Immune-modulation via IgD B-cell receptor suppresses allergic skin inflammation in experimental contact hypersensitivity models despite of a Th2-favoured humoral response. Immunol Lett. 2018;203:29-39. https://doi.org/10.1016/j.imlet.2018.09.008 (Epub 2018 Sep 12).

72. Horiuchi T. Hereditary angioedema from 1888 to 2018-progress and problems. Intern Med. 2018:57:3065-6.

73. Busse PJ, Christiansen SC. Hereditary angioedema. N Engl J Med. 2020;382:1136-48.

74. Longhurst $\mathrm{H}$. Optimum use of acute treatments for hereditary angioedema: evidence-based expert consensus. Front Med (Lausanne). 2018:4:245.

75. Lumry WR, Weller K, Magerl M, et al. Impact of lanadelumab on healthrelated quality of life in patients with hereditary angioedema in the HELP study. Allergy. 2021;76:1188-98. 
76. Maurer M, Magerl M, Ansotegui l, et al. The international WAO/EAAC guideline for the management of hereditary angioedema-The 2017 revision and update. Allergy. 2018;73:1575-96.

77. Cicardi M, Aberer W, Banerji A, et al. Classification, diagnosis, and approach to treatment for angioedema: consensus report from the Hereditary Angioedema International Working Group. Allergy. 2014:69:602-16.

78. Caballero T, Prior N. Burden of illness and quality-of-life measures in angioedema conditions. Immunol Allergy Clin North Am. 2017;37:597-616

79. Weller K, Groffik A, Magerl M, et al. Development and construct validation of the angioedema quality of life questionnaire. Allergy. 2012;67:1289-98.

80. Weller K, Magerl M, Peveling-Oberhag A, et al. The Angioedema Quality of Life Questionnaire (AE-QOL) — assessment of sensitivity to change and minimal clinically important difference. Allergy. 2016;71:1203-9.

81. Morioke S, Takahagi S, Kawano R, et al. A validation study of the Japanese version of the Angioedema Activity Score (AAS) and the Angioedema Quality of Life Questionnaire (AE-QoL). Allergol Int. 2021;S1323-8930(21):00048-54.

82. Kulthanan K, Chularojanamontri L, Rujitharanawong C, et al. Angioedema quality of life questionnaire (AE-QoL) —interpretability and sensitivity to change. Health Qual Life Outcomes. 2019;17:160.

83. Bygum A, Busse P, Caballero T, Maurer M. Disease severity, activity, impact, and control and how to assess them in patients with hereditary angioedema. Front Med (Lausanne). 2017;4:212.

84. Weller K, Zuberbier T, Maurer M. Chronic urticaria: tools to aid the diagnosis and assessment of disease status in daily practice. J Eur Acad Dermatol Venereol. 2015;29(Suppl 3):38-44.

85. Zuberbier T, Aberer W, Asero R, et al. The EAACI/GA²LEN/EDF/WAO guideline for the definition, classification, diagnosis and management of urticaria. Allergy. 2018;73:1393-414.

86. Zuberbier T, Abdul Latiff AH, Abuzakouk M, Aquilina S, et al. The international EAACI/GA²LEN/EuroGuiDerm/APAAACI guideline for the definition, classification, diagnosis, and management of urticaria. Allergy. 2021. https://doi.org/10.1111/all.15090.

87. Prior N, Remor E, Gómez-Traseira C, et al. Development of a diseasespecific quality of life questionnaire for adult patients with hereditary angioedema due to $\mathrm{C} 1$ inhibitor deficiency (HAE-QOL): Spanish multicentre research project. Health Qual Life Outcomes. 2012;10:82.

88. Prior N, Remor E, Pérez-Fernández E, et al. Psychometric field study of Hereditary Angioedema Quality of Life questionnaire for adults: HAEQoL. J Allergy Clin Immunol Pract. 2016;4:464-73.e4.

89. Busse PJ, Christiansen SC, Birmingham JM, et al. Development of a health-related quality of life instrument for patients with hereditary angioedema living in the United States. J Allergy Clin Immunol Pract. 2019;7:1679-83.e7.

90. Lumry WR, Miller DP, Newcomer S, et al. Quality of life in patients with hereditary angioedema receiving therapy for routine prevention of attacks. Allergy Asthma Proc. 2014;35:371-6.

91. Lumry WR, Craig T, Zuraw B, et al. Health-related quality of life with subcutaneous c1-inhibitor for prevention of attacks of hereditary angioedema. J Allergy Clin Immunol Pract. 2018;6:1733-41.e3.

92. Lumry WR, Zuraw B, Cicardi M, et al. Long-term health-related quality of life in patients treated with subcutaneous C1-inhibitor replacement therapy for the prevention of hereditary angioedema attacks: findings from the COMPACT open-label extension study. Orphanet J Rare Dis. 2021;16:86.

93. Kenniston JA, Faucette RR, Martik D, et al. Inhibition of plasma kallikrein by a highly specific active site blocking antibody. J Biol Chem. 2014;289:23596-608.

94. Banerji A, Busse P, Shennak M, et al. Inhibiting plasma kallikrein for hereditary angioedema prophylaxis. N Engl J Med. 2017;376:717-28.

95. Chyung $Y$, Vince $B$, larrobino $R$, et al. A phase 1 study investigating DX-2930 in healthy subjects. Ann Allergy Asthma Immunol. 2014;113:460-6.

96. Banerji A, Riedl MA, Bernstein JA, et al. Effect of lanadelumab compared with placebo on prevention of hereditary angioedema attacks: a randomized clinical trial. JAMA. 2018;320:2108-21.

97. Riedl MA, Bernstein JA, Craig T, et al. An open-label study to evaluate the long-term safety and efficacy of lanadelumab for prevention of attacks in hereditary angioedema: design of the HELP study extension. Clin Transl Allergy. 2017;7:36.

98. Lumry WR, Maurer M, Megerl M, et al. Long-term lanadelumab treatment improves health-related quality of life: HELP open-label extension study interim findings. ACAAI Annual Meeting 2019. Abstract \#P156. https://doi.org/10.1016/j.anai.2019.08.260.

99. Craig TJ, Soteres D, Anderson J, et al. Quality of life of hereditary angioedema (HAE) patients with medical history of depression/anxiety receiving lanadelumab. ACAAI Annual Meeting 2020. Poster \#P163.

100. Hahn J, Trainotti S, Wigand MC, et al. Prospective analysis in patients with HAE under prophylaxis with lanadelumab: a real-life experience. J Drugs Dermatol. 2020;19:978-83.

101. Riedl MA. Critical appraisal of androgen use in hereditary angioedema: a systematic review. Ann Allergy Asthma Immunol. 2015;114:281-8. e287.

102. Rossignol J, Polivka L, Maouche-Chrétien L, Frenzel L, Dubreuil P, Hermine $O$. Recent advances in the understanding and therapeutic management of mastocytosis. F1000Res. 2019;8:F1000 Faculty Rev-1961.

103. Valent P, Akin C, Metcalfe DD. Mastocytosis: 2016 updated WHO classification and novel emerging treatment concepts. Blood. 2017; 129:1420-7

104. Siebenhaar F, Sander B, Ho LHT, Ellrich A, Maurer M, Weller K. Development and validation of the mastocytosis activity score. Allergy. 2018;73(7):1489-96. https://doi.org/10.1111/all.13425 (Epub 2018 Mar 1).

105. van Anrooij B, Kluin-Nelemans JC, Safy M, Flokstra-de Blok BMJ, Oude Elberink JNG. Patient-reported disease-specific quality-of-life and symptom severity in systemic mastocytosis. Allergy. 2016;71(11):1585-93.

106. Vermeiren MR, Kranenburg LW, van Daele PLA, van Wijk GR, Hermans MAW. Psychological functioning and quality of life in patients with mastocytosis: a cross-sectional study. Ann Allergy Asthma Immunol. 2020;124(4):373-378.e2.

107. Jennings S, Russell N, Jennings B, et al. The Mastocytosis Society survey on mast cell disorders: patient experiences and perceptions. J Allergy Clin Immunol Pract. 2014:2:70-6.

108. Nowak A, Gibbs BF, Amon U. Pre-inpatient evaluation on quality and impact of care in systemic mastocytosis and the influence of hospital stay periods from the perspective of patients: a pilot study. J Dtsch Dermatol Ges. 2011;9(7):525-32 (English, German).

109. Hermine O, Lortholary O, Leventhal PS, et al. Case-control cohort study of patient's perceptions of disability in mastocytosis. PLOS ONE. 2008:3:e2266

110. Jensen B, Broesby-Olsen S, Bindslev-Jensen C, Nielsen DS. Everyday life and mastocytosis from a patient perspective-a qualitative study. J Clin Nurs. 2019;28(7-8):1114-24.

111. Pulfer S, Ziehfreund S, Gebhard J, Hindelang B, Biedermann T, Brockow $K$, Zink A. Health-related quality of life and influencing factors in adults with nonadvanced mastocytosis - a cross-sectional study and qualitative approach. J Allergy Clin Immunol Pract. 2021;S22132198(21):00565-71. https://doi.org/10.1016/j.jaip.2021.04.059.

112. Siebenhaar F, von Tschirnhaus E, Hartmann K, Rabenhorst A, Staubach P, Peveling-Oberhag A, Wagner N, Martus P, Carter MC, Metcalfe DD, Church MK, Maurer M, Weller K. Development and validation of the mastocytosis quality of life questionnaire: MC-QoL. Allergy. 2016;71(6):869-77.

113. Jennings SV, Slee VM, Zack RM, Verstovsek S, George TI, Shi H, Lee P, Castells MC. Patient perceptions in mast cell disorders. Immunol Allergy Clin North Am. 2018;38(3):505-25.

114. Georgin-Lavialle S, Moura DS, Salvador A, et al. Mast cells' involvement in inflamamtion pathways linked to depression: evidence in mastocytosis. Mol Psychiatry. 2016;21:1511-6.

115. Siebenhaar F, Förtsch A, Krause K, Weller K, Metz M, Magerl M, Martus $\mathrm{P}$, Church MK, Maurer M. Rupatadine improves quality of life in mastocytosis: a randomized, double-blind, placebo-controlled trial. Allergy. 2013;68(7):949-52. https://doi.org/10.1111/all.12159 (Epub 2013 Jun 4).

116. Hartmann K, Gotlib J, Akin C, Hermine O, Awan FT, Hexner E, Mauro MJ, Menssen HD, Redhu S, Knoll S, Sotlar K, George TI, Horny HP, Valent P, Reiter A, Kluin-Nelemans HC. Midostaurin improves quality of life and mediator-related symptoms in advanced systemic mastocytosis. J Allergy Clin Immunol. 2020;146(2):356-366.e4. 
117. Jendoubi F, Gaudenzio N, Gallini A, Negretto M, Paul C, Bulai LC. Omalizumab in the treatment of adult patients with mastocytosis: a systematic review. Clin Exp Allergy. 2020;50(6):654-61.

118. Broesby-Olsen S, Vestergaard H, Mortz CG, Jensen B, Havelund T, Hermann AP, Siebenhaar F, Møller MB, Kristensen TK, Bindslev-Jensen C, Mastocytosis Centre Odense University Hospital (MastOUH). Omalizumab prevents anaphylaxis and improves symptoms in systemic mastocytosis: efficacy and safety observations. Allergy. 2018;73(1):230-8.

119. Nettis E, Foti C, Ambrifi M, Baiardini I, Bianchi L, Borghi A, et al. Urticaria: recommendations from the Italian Society of allergology, asthma and clinical immunology and the Italian society of allergological, occupational and environmental dermatology. Clin Mol Allergy. 2020;18:8. https://doi.org/10.1186/s12948-020-00123-8.

120. Fricke J, Ávila G, Keller T, Weller K, Lau S, Maurer M, et al. Prevalence of chronic urticaria in children and adults across the globe: systematic review with meta-analysis. Allergy. 2020;75(2):423-32. https://doi.org/ 10.1111/all.14037 (Epub 2019 Oct 11).

121. Baiardini I, Braido F, Bindslev-Jensen C, et al. Recommendations for assessing patient-reported outcomes and health-related quality of life in patients with urticaria: a GA(2) LEN taskforce position paper. Allergy. 2011;66:840-4.

122. O'Donnell BF, Lawlor F, Simpson J, Morgan M, Greaves MW. The impact of chronic urticaria on the quality of life. Br J Dermatol. 1997;136:197-201.

123. Hawro T, Ohanyan T, Schoepke N, Metz M, Peveling-Oberhag A, Staubach $P$, et al. The urticaria activity score-validity, reliability, and responsiveness. J Allergy Clin Immunol Pract. 2018;6(4):1185-1190.e1. https://doi.org/10.1016/j.jaip.2017.10.001.

124. Weller K, Groffik A, Church MK, Hawro T, Krause K, Metz M, et al. Development and validation of the Urticaria Control Test: a patient-reported outcome instrument for assessing urticaria control. J Allergy Clin Immunol. 2014;133(5):1365-72.e6. https://doi.org/10.1016/j.jaci.2013.12. 1076.

125. Weller K, Groffik A, Magerl M, Tohme N, Martus P, Krause K, et al. Development, validation, and initial results of the Angioedema Activity Score. Allergy. 2013;68(9):1185-92. https://doi.org/10.1111/all.12209 (Epub 2013 Aug 6).

126. Weller K, Magerl M, Peveling-Oberhag A, Martus P, Staubach P, Maurer M. The Angioedema Quality of Life Questionnaire (AE-QoL)—assessment of sensitivity to change and minimal clinically important difference. Allergy. 2016;71(8):1203-9. https://doi.org/10.1111/all.12900 (Epub 2016 Jun 13).

127. Finlay AY, Khan GK. Dermatology Life Quality Index (DLQI)—a simple practical measure for routine clinical use. Clin Exp Dermatol. 1994;19:210-6.

128. Maurer M, Abuzakouk M, Bérard F, Canonica W, Oude Elberink H, Giménez-Arnau A, et al. The burden of chronic spontaneous urticaria is substantial: real-world evidence from ASSURE-CSU. Allergy. 2017;72(12):2005-16. https://doi.org/10.1111/all.13209 (Epub 2017 Jul 10).

129. Curto-Barredo L, Archilla L, Vives G, Pujol R, Giménez-Arnau A. Clinical features of chronic spontaneous urticaria that predict disease prognosis and refractoriness to standard treatment. Acta Derm Venereol. 2018;98(7):641-7.

130. Antia C, Baquerizo K, Korman A, Alikhan A, Bernstein JA. Urticaria: a comprehensive review. J Am Acad Dermatol. 2018;79(4):617-33.

131. Marin-Cabanas I, Berbegal-de Gracia L, Leon-Marrero F, et al. Management of chronic spontaneous urticaria in routine clinical practice following the EAACI/GA2LEN/EDF/WAO Guidelines. Actas Dermosifiliogr. 2017;108:346-53.

132. Guillen-Aguinaga S, Jauregui Presa I, Aguinaga-Ontoso E, et al. Updosing nonsedating antihistamines in patients with chronic spontaneous urticaria: a systematic review and. Br J Dermatol. 2016;175:1153-65.

133. Farre M, Perez-Mana C, Papaseit E, Menoyo E, Pérez M, Martin S, et al. Bilastine vs. hydroxyzine: occupation of brain histamine $\mathrm{H} 1$-receptors evaluated by positron emission tomography in healthy volunteers. $\mathrm{Br} J$ Clin Pharmacol. 2014;78:970-80.

134. Hide M, Yagami A, Togawa M, Saito A, Furue M. Efficacy and safety of bilastine in Japanese patients with chronic spontaneous urticaria: a multi-center, randomized, double-blind, placebo-controlled, parallelgroup phase II/III study. Allergol Int. 2017;66:317-25.
135. Yagami A, Furue M, Togawa M, Saito A, Hide M. One-year safety and e cacy study of bilastine treatment in Japanese patients with chronic spontaneous urticaria or pruritus associated with skin diseases. J Dermatol. 2017:44:375-85.

136. Demonte A, Guanti MB, Liberati S, Biffi A, Fernando F, Fainello M, Pepe P. Bilastine safety in drivers who need antihistamines: new evidence from high-speed simulator driving test on allergic patients. Eur Rev Med Pharmacol Sci. 2018;22(3):820-8.

137. Podder I, Das A, Ghosh S, Biswas D, Sengupta S, Chowdhury SN. Effectiveness, safety, and tolerability of bilastine $20 \mathrm{mg}$ vs levocetirizine $5 \mathrm{mg}$ for the treatment of chronic spontaneous urticaria: a double-blind, parallel group, randomized controlled trial. Dermatol Ther. 2020;33(6):e13946.

138. Zuberbier T, Oanta A, Bogacka E, Medina I, Wesel F, Uhl P, Antépara I, Jáuregui I, Valiente R. Comparison of the efficacy and safety of bilastine $20 \mathrm{mg}$ vs levocetirizine $5 \mathrm{mg}$ for the treatment of chronic idiopathic urticaria: a multi-centre, double-blind, randomized, placebo-controlled study. Bilastine Int Working Group. Allergy. 2010;65(4):516-28.

139. Zhao ZT, Ji CM, Yu WJ, et al. Omalizumab for the treatment of chronic spontaneous urticaria: a meta-analysis of randomized clinical trials. $J$ Allergy Clin Immunol. 2016;137:1742-50.

140. Saini S, Rosen KE, Hsieh HJ, et al. A randomized, placebo-controlled, dose-ranging study of single-dose omalizumab in patients with H1-antihistamine-refractory chronic idiopathic urticaria. J Allergy Clin Immunol. 2011;128:567-73.

141. Sussman G, Hebert J, Barron C, et al. Real-life experiences with omalizumab for the treatment of chronic urticaria. Ann Allergy Asthma Immunol. 2014;112(2):170-4.

142. Metz M, Ohanyan T, Church MK, Maurer M. Omalizumab is an effective and rapidly acting therapy in difficult-to-treat chronic urticaria: a retrospective clinical analysis. J Dermatol Sci. 2014;73(1):57-62.

143. Zazzali JL, Kaplan A, Maurer M, et al. Angioedema in the omalizumab chronic idiopathic/spontaneous urticaria pivotal studies. Ann Allergy Asthma Immunol. 2016;117:370-7.

144. Finlay AY, Kaplan AP, Beck LA, Antonova EN, Balp MM, Zazzali J, Khalil S, Maurer M. Omalizumab substantially improves dermatologyrelated quality of life in patients with chronic spontaneous urticaria. J Eur Acad Dermatol Venereol. 2017;31(10):1715-21.

145. Agache I, Rocha C, Pereira A, Song Y, Alonso-Coello P, Solà I, et al. Efficacy and safety of treatment with omalizumab for chronic spontaneous urticaria: a systematic review for the EAACI Biologicals Guidelines. Allergy. 2021;76:59-70.

146. Tharp MD, Bernstein JA, Kavati A, et al. Benefits and harms of omalizumab treatment in adolescent and adult patients with chronic idiopathic (spontaneous) urticaria: a meta-analysis of "real-world" evidence. JAMA Dermatol. 2019;155(1):29-38. https://doi.org/10. 1001/jamadermatol.2018.3447.

147. Bernstein JA, Kavati A, Tharp MD, Ortiz B, MacDonald K, Denhaerynck $K$, et al. Effectiveness of omalizumab in adolescent and adult patients with chronic idiopathic/spontaneous urticaria: a systematic review of 'real-world' evidence. Expert Opin Biol Ther. 2018;18(4):425-48. https://doi.org/10.1080/14712598.2018.1438406.

148. Metz M, Vadsz Z, Kocatùrk E, Gimenez-Arnau AM. Omalizumab updosing in chronic spontaneous urticaria: an overview of real-world evidence. Clin Rev Allergy Immunol. 2020;59:38-45.

149. Maurer M, Weller K, Bindslev-Jensen C, Giménez-Arnau A, Bousquet $\mathrm{P}$, Bousquet J, et al. Unmet clinical needs in chronic spontaneous urticarial. A GA2LEN task force report 1. Allergy. 2011;66:317-30.

150. Saini SS, Bindslev-Jensen C, Maurer M, et al. Efficacy and safety of omalizumab in patients with chronic idiopathic/spontaneous urticaria who remain symptomatic on $\mathrm{H} 1$-antihistamines: a randomized, placebo-controlled study. J Invest Dermatol. 2015;135:67-75.

151. Maurer M, Rosen $\mathrm{K}$, Hsieh HJ, et al. Omalizumab for the treatment of chronic idiopathic or spontaneous urticaria. N Engl J Med. 2013;368:924-9354.

152. Staubach P, Metz M, Chapman-Rothe N, Sieder C, Bräutigam M, Maurer $\mathrm{M}$, et al. Omalizumab rapidly improves angioedema-related quality of life in adult patients with chronic spontaneous urticaria: X-ACT study data. Allergy. 2018;73:576-84. 
153. Maurer M, Sofen H, Ortiz B, Kianifard F, Gabriel S, Bernstein J. Positive impact of omalizumab on angioedema and quality of life in patients with refractory chronic idiopathic/spontaneous urticaria: analyses according to the presence or absence of angioedema. J Eur Acad Dermatol Venereol. 2017;31:1056-63.

154. Azofra J, Diaz C, Antepara I, Jauregui I, Soriano A, Ferrer M. Positive response to omalizumab in patients with acquired idiopathic nonhistaminergic angioedema. Ann Allergy Asthma Immunol. 2015:114:418-9.

155. Grattan CE, O'Donnell BF, Francis DM, et al. Randomized double-blind study of cyclosporin in chronic 'idiopathic' urticaria. Br J Dermatol. 2000;143:365-72.

156. Vena GA, Cassano N, Colombo D, Peruzzi E, Pigatto P. Cyclosporine in chronic idiopathic urticaria: a double-blind, randomized, placebocontrolled trial. J Am Acad Dermatol. 2006;55:705-9.

157. Kulthanan K, Chaweekulrat P, Komoltri C, et al. Cyclosporine for chronic spontaneous urticaria: a meta-analysis and systematic review. J Allergy Clin Immunol Pract. 2018;6(2):586-99.

158. Savic S, Marsland A, McKay D, Ardern-Jones MR, Leslie T, Somenzi O, et al. Retrospective case note review of chronic spontaneous urticaria outcomes and adverse effects in patients treated with omalizumab or ciclosporin in UK secondary care. Allergy Asthma Clin Immunol. 2015;11(1):21.

159. Kolkhir P, Altrichter S, Munoz M, Hawro T, Maurer M. New treatments for chronic urticaria. Ann Allergy Asthma Immunol. 2020;124(1):2-12.

160. Maurer M, Giménez-Arnau AM, Sussman G, Metz M, Baker DR, Bauer A. Ligelizumab for chronic spontaneous urticaria. N Engl J Med. 2019;381(14):1321-32.

161. Lee JK, Simpson RS. Dupilumab as a novel therapy for difficult to treat chronic spontaneous urticaria. J Allergy Clin Immunol Pract. 2019;7(5):1659-61.

162. Maurer M, Altrichter S, Metz M, Zuberbier MKT, Church MK, Bergmann KC. Benefit from reslizumab treatment in a patient with chronic spontaneous urticaria and cold urticaria. JEADV. 2018;32:e86-121.

\section{Publisher's Note}

Springer Nature remains neutral with regard to jurisdictional claims in published maps and institutional affiliations.

Ready to submit your research? Choose BMC and benefit from:

- fast, convenient online submission

- thorough peer review by experienced researchers in your field

- rapid publication on acceptance

- support for research data, including large and complex data types

- gold Open Access which fosters wider collaboration and increased citations

- maximum visibility for your research: over 100M website views per year

At BMC, research is always in progress.

Learn more biomedcentral.com/submissions 